\title{
Community Networks and Sustainability: a Survey of Perceptions, Practices, and Proposed Solutions
}

\author{
Panagiota Micholia*, Merkouris Karaliopoulos*, Iordanis Koutsopoulos *, Leandro Navarro ${ }^{\dagger}$, \\ Roger Baig ${ }^{\dagger}$, Dimitris Boucas ${ }^{\ddagger}$, Maria Michalis ${ }^{\ddagger}$, Panayiotis Antoniadis ${ }^{\S}$ \\ * Athens University of Economics and Business , ${ }^{\dagger}$ Universitat Politècnica de Catalunya , \\ ${ }^{\ddagger}$ University of Westminster, ${ }^{\S}$ NetHood Zurich \\ \{panamixo,jordan, mkaralio\}@aueb.gr, \{leandro, rbaig\}@ac.upc.edu, \\ \{D.Boucas, M.Michalis\}@westminster.ac.uk, panayotis@nethood.org
}

\begin{abstract}
Index Terms-Community networks, sustainability, incentive mechanisms.

Abstract-Community network (CN) initiatives have been around for roughly two decades, evangelizing a distinctly different paradigm for building, maintaining, and sharing network infrastructure but also defending the basic human right to Internet access. Over this time they have evolved into a mosaic of systems that vary widely with respect to their network technologies, their offered services, their organizational structure, and the way they position themselves in the overall telecommunications' ecosystem. Common to all these highly differentiated initiatives is the sustainability challenge.

We approach sustainability as a broad term with an economical, political, and cultural context. We first review the different perceptions of the term. These vary both across and within the different types of stakeholders involved in CNs and are reflected in their motivation to join such initiatives. Then, we study the diverse approaches of $\mathrm{CN}$ operators towards the sustainability goal. Given the rich context of the term, these range all the way from mechanisms to fund their activities, to organizational structures and social activities serving as incentives for the engagement of their members. We iterate on incentive mechanisms that have been proposed and theoretically analyzed in the literature for CNs as well as tools and processes that have been actually implemented in them. Finally, we enumerate lessons that have been learned out of these two decades of CNs' operation and discuss additional technological and regulatory issues that are key to their longer-term sustainability.
\end{abstract}

\section{INTRODUCTION}

Community networks (CNs) are networks inspired, built and managed by citizens and non-profit organizations. They are crowdsourced initiatives, whereby people combine their efforts and resources to collectively instantiate communication network infrastructures. Typically, CNs are initiated by small groups of people who more often than not are driven by strong cultural and political motives. Such motives include the fight against the digital divide through the provision of telecommunication services in under-served areas; the desire for autonomy and self-organization practices; the right to open, neutral networks and privacy; the opportunity to experiment with technology in do-it-yourself manner; and the commitment to community ideals and needs.

CNs originally surfaced in the late 90 s and have taken many forms and shapes ever since. Whereas some of them have become obsolete due to the rise of commercial high speed broadband networks in the areas they operated, others have flourished and evolved into alternative telecommunication network models (section I-A). Not only have they filled in the coverage gaps of commercial operators providing telecommunication services in rural under-served areas, but they have also developed rich organizational frameworks with innovative tools and mechanisms. Typically, these frameworks emerge and evolve empirically as a result of past experiences, successful and unsuccessful practices and accumulated knowledge. They are meant to systematize the network's governance, management and operation processes and ensure the viability of CNs. The establishment of sustainable economic models is a key factor to this end.

\section{A. Current motivating factors and new paths for CNs}

While community networks focus on satisfying the needs of local communities, there are currently good reasons motivating a more active role in the overall telecommunications landscape.

1) Contributing to broadband connectivity goals: Broadband Internet access has been promoted as a core priority of top-level political agendas throughout the world. This is reflected in initiatives such as the Sustainable Development Goals (SDG) of the United Nations (in the SDG9 about resilient infrastructures) and the treatment of broadband access as a key issue in the Internet Society and the International Telecommunications Union (ITU) among others. In Europe, for example, the European Commission (EC) has set ambitious policy objectives for the years to come, summarized under the EC broadband $2020^{1}$ and $2025^{2}$ agendas. The realization of these agendas demands huge investment costs on network infrastructure, thus favoring approaches that share these costs among different stakeholders. Grassroots initiatives such as $\mathrm{CNs}$ are explicitly acknowledged as one possible approach to amortize the network infrastructure deployment costs and one of four ways to involve public authorities in the realization of the broadband vision [1]. Community broadband networks such as the guifi.net in Catalonia, Spain [2], RemIX [3] and

\footnotetext{
${ }^{1}$ https://ec.europa.eu/digital-single-market/en/broadband-strategy-policy

${ }^{2}$ https://ec.europa.eu/digital-single-market/en/broadband-europe
} 


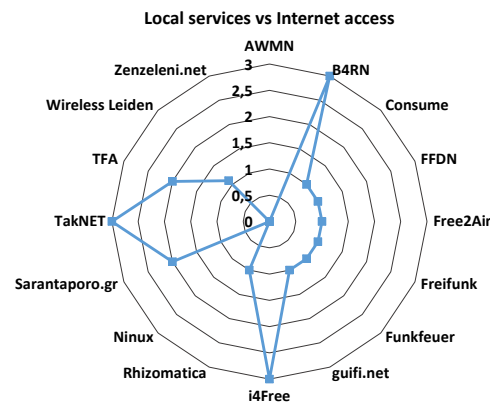

(a)

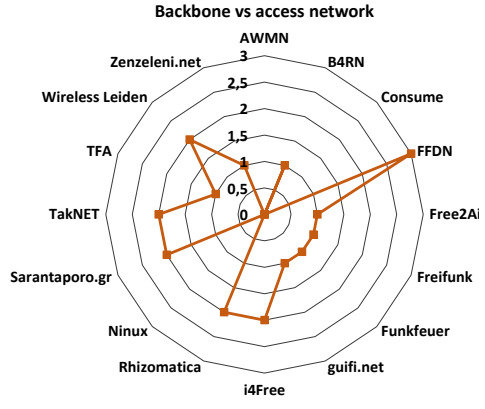

(b)

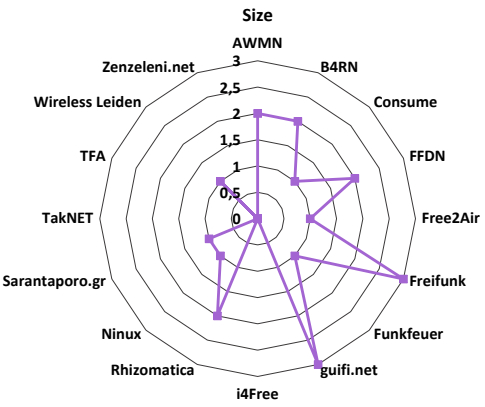

(c)

Fig. 1: Radar charts following $\mathrm{CN}$ characteristics i.e., types of services and infrastructure used, number of participating nodes (a) CN services. 0: local services as default (Internet connectivity available upon request, manual configuration), 1: mix of local services and Internet connectivity, 2: Internet connectivity as the main service (only management tools as local services), 3: Internet connectivity only. (b) CN Infrastructure types. 0: the greatest part of the network is composed of backbone nodes, there is a small number of access nodes, 1: the network is divided equally between the number of backbone nodes and the number of access nodes, 2: the greatest part of the network is composed of access nodes, there are a few backbone nodes, 3: the network is composed by access nodes only (no backbone nodes). (c) CN Size. 0: Very small (number of nodes $<100$ ), 1: Small $(100<$ number of nodes $<1000)$, 2 : Medium $(1000<$ number of nodes $<10.000)$, 3: Large (number of nodes $>10.000)$.

B4RN [4] in United Kingdom, are singled out as best practices in this respect at the $\mathrm{EC}$ website.

2) Providing Internet access in developing regions: More than half of the world population, in particular, the poor and marginalized populations in developing areas, are still offline [5]. In response to this fact, many large industrial corporations such as Google, Microsoft and Facebook have stated ambitious objectives to connect another billion users around the globe.

Google launched Loon, a project aiming to reach uncovered areas and offer them Internet connection using balloons flying in the stratosphere. Facebook has been experimenting with a high-altitude solar drones for providing Internet access around the world. ${ }^{3}$ At the same time, Microsoft plans to bring Internet to remote areas utilizing TV white spaces and collaborating with telecommunication operators.

Community networks are well positioned to stand as alternatives and/or complements to such global initiatives and provide realistic implementation paths to their ambitious objectives. Combining the Do-It-Yourself culture with provisions for unlicensed spectrum and cheap fibre, small crowdfunded community operators that create local value for the local people, without need for complex and centralized systems, may be the obvious way to go about realizing the vision of Internet access to developing regions.

3) Democratization of the telecommunication market: The market of telecom services is usually composed of monopolies and oligopolies that concentrate significant amount of power. The prevention of telecommunications market distortions and the openness of networks is acknowledged as a key goal by

\footnotetext{
${ }^{3}$ These two projects could be viewed as an evolution of the original HAPs (High Altitude Platforms) concept. HAPs, such as balloons or unmanned planes in circular orbits in the air, were proposed already in late 90 s for providing Internet connection to rural areas lacking fixed network infrastructure
}

the ITU [6], the EC [1], and the Organization for Economic Cooperation and Development (OECD) [7]. Monopolies lead to vertically integrated models, where all the layers of the network belong to one entity and end users are left with limited options when it comes to choosing an operator.

The decentralized way in which they are built and operated makes $\mathrm{CNs}$ an ideal candidate model for separating the network infrastructure from the service provision layer. This separation generates opportunities for sharing the related costs between multiple players and opening the network to public administrations and commercial entities such as local/regional ISPs (we elaborate on this model in section II.C).

\section{B. Survey focus, methodological approach, and sources}

Our survey does not aim at presenting the status of the hundreds of $\mathrm{CN}$ efforts around the globe, nor is it a review of the technologies used in CNs today. Such information is already available in the $\mathrm{CN}$ literature [8], [9], [10]. Instead, the focus of this survey is on the multiple, often complementary, ways different $\mathrm{CN}$ initiatives pursue their sustainability. We approach sustainability as a multi-faceted term, with technical, economic, socio-cultural and political context. We review how these networks fund their activities; which ones have been the dominant motives behind their initiation and which ones are the aspirations of other actors when participating in them; and what kind of tools and processes are in place as incentives in the different CNs to best respond to these motives and aspirations.

Most of the material for this survey originates from interviews, both in-person and questionnaire-based, carried out in the context of the netCommons R\&D project [11], [12]. Another big part, on proposed participation incentives and mechanisms, is the result of an exhaustive review of the existing scientific literature on the topic. Sixteen $\mathrm{CNs}$ are 


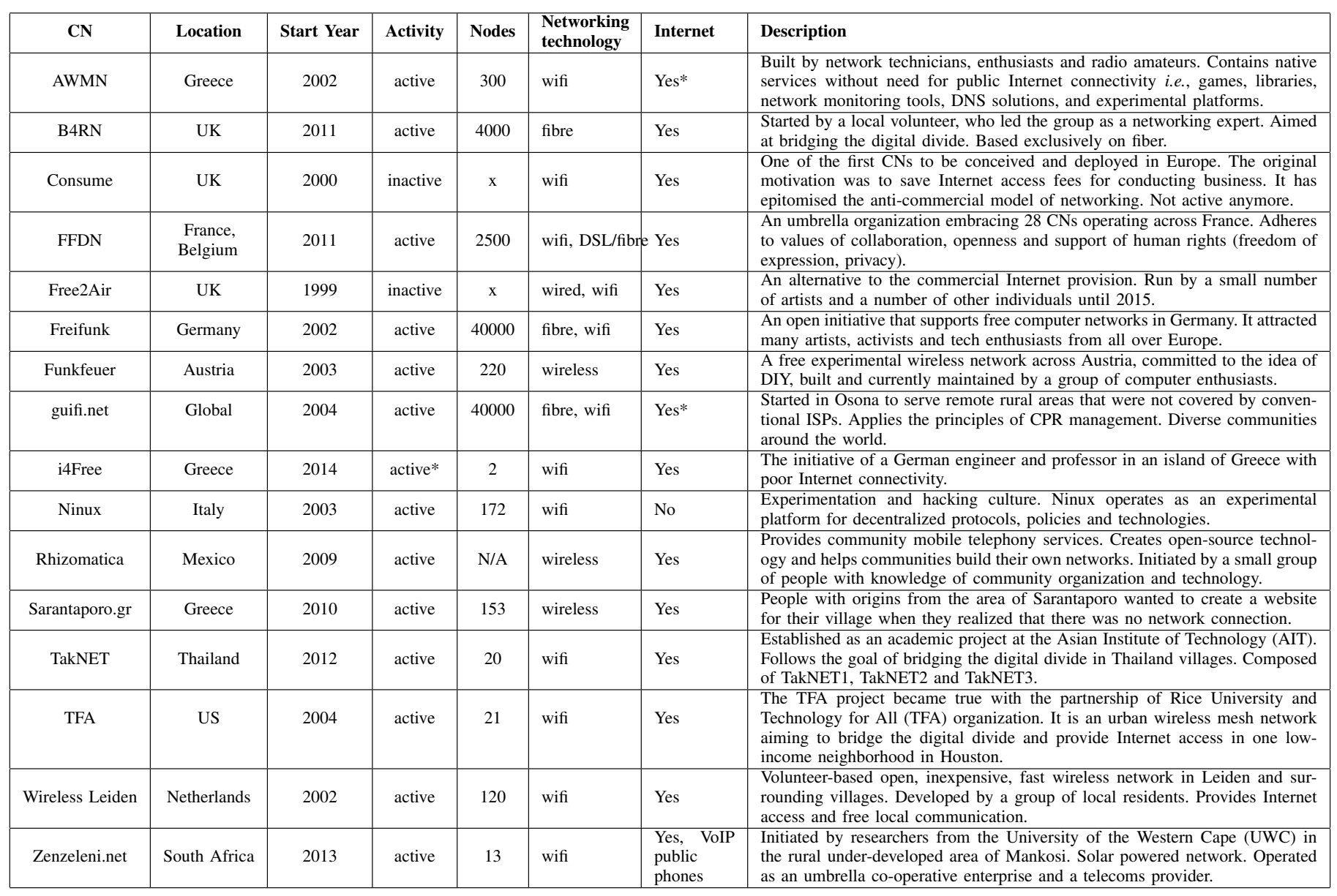

TABLE I: Basic information about $16 \mathrm{CN}$ instances that are analyzed further in the survey. These are chosen as representative instances of the rich variety of worldwide CNs.

primarily discussed in this paper, as listed in Table I-A2. They are selected as good representatives of the diversity in existing CNs with respect to size (local vs. regional), supported services (local services $v s$. Internet access), network scope/role (backbone network vs. access network), geographical area of coverage (urban areas with rich communication alternatives vs. rural under-served areas), organizational structure (involved actors and decision-making processes), and funding sources. The radar chart of Fig. 1 depicts how these sixteen $\mathrm{CNs}$ score on the first three attributes (size, services, network role) on a 0-3 scale.

In the remainder of the survey, we first present the layered network infrastructure model, which aims at maximal openness and actors' involvement, and explore how CNs fit in it as open access network instances (section II). Then, in section III, we iterate on the participation motives of different actors and their implications for the $\mathrm{CN}$ sustainability. In section IV, we elaborate on the economic sustainability aspects and the funding sources of CNs; we also review some theoretical models addressing the economic sustainability question. We describe in section $\mathrm{V}$ incentive mechanisms that are either practiced in different $\mathrm{CNs}$ or theoretically analyzed in the literature. Section VI enumerates the most valuable insights out of the survey, whereas section VII iterates on additional challenges $\mathrm{CN}$ face at technical and regulations level. We conclude the paper in section VIII.

\section{NETWORK INFRASTRUCTURES AND COMMUNITY NETWORKS}

In this section, we seek to position CNs within the broader picture of broadband communication networks. To this end, we first describe what kind of infrastructure is typically deployed in most CNs and the technologies they use. Then, we present a layered model of network infrastructures that eases the discussion of different operational business models met in contemporary networks. Finally, we clarify how $\mathrm{CNs}$ position with respect to this model and the implications for their sustainability.

\section{A. CN infrastructure and technologies in use}

While a great number of CNs have utilized Wi-Fi to build their networks and reduce infrastructure costs, others have developed solutions based on fibre (e.g., BARN) or cellular connectivity (e.g., Rhizomatica). In some cases (i.e., FFDN, guifi.net), they have created federations of local networks, where different types of technologies co-exist. The specificities of each geographic area, the feasibility of different network topologies, the deployment and maintenance cost, as well as the profile of services attracting demand in each case, 


\begin{tabular}{|l|l|}
\hline Acronym & Description \\
\hline AP & Access Point \\
\hline CAPEX & Capital Expenditure \\
\hline CN & Community Network \\
\hline CONFINE & Community Networks Testbed for the Future Internet \\
\hline CPR & Common Pool Resource \\
\hline CS & Community Service \\
\hline DIY & Do-It-Yourself \\
\hline DNS & Domain Name Server \\
\hline EC & European Commission \\
\hline EU & European Union \\
\hline GFOSS & Greek Free/Open Source Software Society \\
\hline ICT & Information and Communication Technology \\
\hline ISP & Internet Service Provider \\
\hline ITU & International Telecommunications Union \\
\hline MANET & Mobile Ad-hoc Networks \\
\hline NCL & Network Commons License \\
\hline NP & Network Provider \\
\hline NPO & Non-Profit Organization \\
\hline OECD & Organization for Economic Cooperation and Development \\
\hline OPEX & Operational Expenditure \\
\hline P2P & Peer to Peer \\
\hline P2PWNC & Peer-to-peer Wireless Network Confederation \\
\hline PIP & Physical Infrastructure Provider \\
\hline SP & Service Provider \\
\hline VoIP & Voice over Internet Protocol \\
\hline WCED & World Commission Environment and Development \\
\hline WCL & Wireless Commons License \\
\hline
\end{tabular}

TABLE II: Terminology used throughout the paper.

may favor one technology or another or a combination of technologies (TableI-A2).

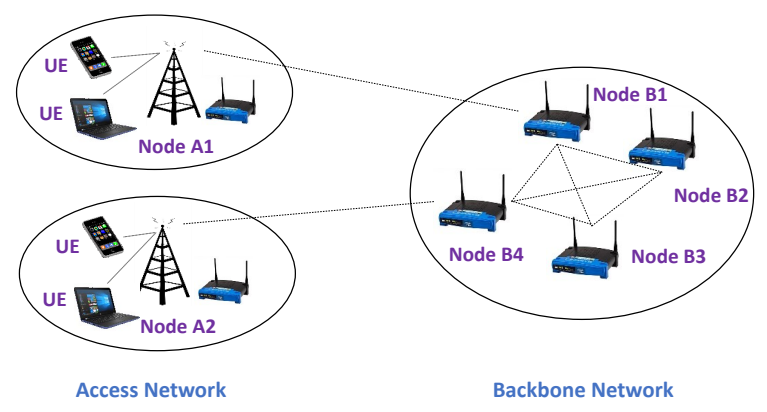

Fig. 2: Backbone and access nodes in a wireless mesh network using Wi-Fi.

The key component of a $\mathrm{CN}$ is a network node (a router). Nodes are devices that either relay the network's data (backbone nodes) or provide network access (access points or access nodes) to end-user devices (client nodes). The set of backbone nodes constitutes the backbone network and the set of access nodes forms the access network (Fig.2). Topologies differ depending on the way nodes are arranged within the network, the way they form links between them, and whether links are point-to-point or point-to-multipoint. Links can be either wireless (Wi-Fi, cellular) or wired (fiber, DSL etc.) so that both the backbone and the access network may use wired or wireless technology options for connecting backbone nodes and the end user (UE), respectively. The combination of technologies is also quite common in most networks, where wireless technology complements a wired network and vice versa.

- Wireless technologies: Wi-Fi is used in point-to-point mode to bridge long distances or in mesh topology to cover areas. A mesh topology refers to nodes that tend to connect with each other directly rather than through a hierarhical tree or ring topology. This feature allows connecting the nodes through multiple independent paths. If one link is broken or degraded, an alternative route can always compensate for it.

Another type of wireless technology used in the access network is cellular, mainly the GSM technology, even if it is outdated in many areas worldwide. Access nodes are basically base stations that connect mobile users. The cellular technology divides the area into cells and installs fixed radio towers to support the coverage in each cell. The used frequencies are different from the ones used in Wi-Fi. Notably, operation in these bands requires the acquisition of a license, in contrast to the free and unlicensed Wi-Fi frequency bands.

- Wired technologies: Fiber is a medium that offers large bandwidth and low interference for the transmission of information, resulting in very high data rates. In principle, it can be used to construct an entire telecommunication network (backbone and access network) or a part of it. Due to its high cost, it is most commonly used in the backbone network, combined with Wi-Fi access. However, there are exemplary cases of low-cost rural fiber self-deployments such as in the B4RN and guifi.net CNs. An alternative wired technology in use is the DSL technology, which utilizes telephone lines to transmit telecommunication services. The FFDN network leases such lines to provide Internet access to its members. It is the most economical wired solution for $\mathrm{CN}$ development, thanks to the pre-existing telephony network installations and infrastructure.

\section{B. Network infrastructure layers}

Considering how a broadband network is created, its structure can be decomposed into three distinct but inter-dependent layers: a) passive infrastructure, b) active infrastructure and c) services.

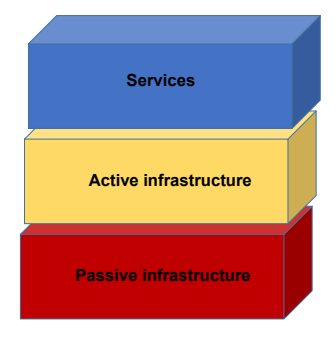

Fig. 3: The layers of a broadband network.

The passive infrastructure layer consists in the required non-electronic physical equipment for deploying the network. 
Non-electric elements vary depending on the link technology in use, e.g., fiber, copper, radio. They typically refer to ducts, cables, masts, towers, technical premises, easements etc.. The passive infrastructure is built to endure for many years, usually decades. Its development demands high capital expenditure (CAPEX) and frequent upgrades are difficult to realize. However, its operational costs (OPEX) are relatively low.

The second layer, i.e., active infrastructure, denotes the electronic physical equipment of a network such as routers, switches, antennas, transponders, control and management servers. The OPEX of the active equipment is high (e.g., electricity costs) but its capital expenditure is usually low since it involves up-to-date technological elements. The active equipment needs to follow the rapid advances of technology and get renewed frequently, i.e., more than once within a decade.

The third and highest layer of a broadband network is the layer of services. It corresponds to the telecommunication services provided on top of the passive and active infrastructure. These services may be both private and public and include electronic government, education, health, e-commerce, Internet access, entertainment, telephony (e.g., VoIP), access to media content (television, radio, movies) and many more. End users usually pay a fee for receiving the services either directly or indirectly. The type of reimbursement depends on the chosen network infrastructure model and the involved business actors.

The implementation of the service layer is conditioned on the deployment of the passive and active infrastructure. Therefore, the first two layers are a prerequisite for the existence of the third one (Fig.3).

\section{Business actors}

Business actors are determined in accordance with the network infrastructure layers [1],[13],[14],[8]. They are typically providers of the network equipment and services. Telecom operators and private companies, public authorities, local cooperatives and housing associations, are some characteristic examples of business actors.

In detail, the physical infrastructure provider (PIP) has ownership of the passive equipment and undertakes the equipment maintenance and operation responsibilities. PIPs can be divided into backbone PIPs and access area PIPs, depending on which network parts they possess. Backbone PIPs invest in the backbone network infrastructure, while access area PIPs own and moderate the infrastructure aimed for providing connections to the end users, i.e., first-mile connectivity. In the case of CNs, a local organization may participate as a backbone PIP, an access PIP or both.

The network provider (NP) owns and operates the active equipment. It leases physical infrastructure installations from the PIPs and makes its equipment available for the provision of services by other SPs or provides its own services. Network providers may be public authorities, private companies, local cooperatives who own the equipment or entities who are subcontracted to operate them by one of the aforementioned owner entities.
The service provider offers services within the network. Service providers are typically companies that utilize the network's active and passive equipment to offer their services to end users in exchange for compensation, typically payment. The payment can be direct (service fee) or indirect (connection or network fee). They need access to the NP's interface and install their own devices if and where needed. The provision of services within the network is vital for the end user engagement and therefore the network's viability.

\section{Network infrastructure business models}

The roles and responsibilities of different business actors in network infrastructures vary, resulting in a great range of business models (Fig. 4). Traditional telecom models follow the concept of vertical integration. In these models, the ownership and operation of all three infrastructure layers is concentrated in one single entity. As a consequence, cases of monopolies or oligopolies that hamper the existence of competitors by exercising great control over the market, i.e., "market failure" cases, are common. Moreover, due to lack of other competing entities, a single vertically integrated operator is often not willing to provide broadband access to remote areas featuring high network expansion costs, leaving several rural areas under-served. To reverse this picture, the ITU [6] and the EC [1], have set as primary goal the promotion of infrastructure separation and sharing through legislation, regulation and subsidies. Open access networks have been brought to focus in this respect.

The openness of a network is characterized by the presence of multiple providers in the market offering customers the opportunity to choose between them. Open access network models separate the ownership from the use of infrastructure layers (i.e., PIP, NP, SP), in order to promote competition, enable the sharing the network infrastructure costs and discourage vertical integration.

Figure 4 captures the possible models that can emerge with respect to the functional separation across layers, as recommended by ITU [6]. Although the borderline between the respective actors is not always clearcut, they range all the way from vertical integration across all layers in $e, f, g$, to partial separation in $a, b, d$, and full functional separation in $c$. The models imply different alternatives and therefore competition at each layer, except for the passive infrastructure, where a single actor is typically in charge of deploying and operating either the backbone or the access area PIP. Whereas all models except for $g$ offer alternatives with respect to service provision, only $d, e$ provide alternatives regarding network provision.

Diverse types of local cooperative schemes can fit in these models. Municipal networks focus on maximizing connectivity from public (municipal) interest point of view. They usually rely on public-private partnerships. The service is defined and governed by the public partner but implemented and operated by one or multiple private partners. Typical examples are the optical fiber service from Stokab in the Stockholm region, among several other regions in Europe, which follows the $d$ model; or the public WiFi services in most European cities, 


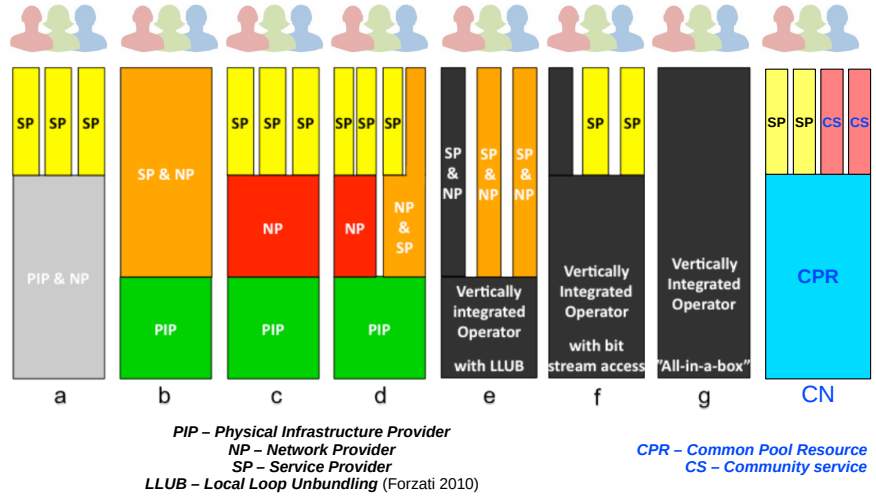

Fig. 4: The components of a broadband network (with a focus on optical fiber) and the three network infrastructure layers.

which can follow any model for service provision as the public entity just defines, funds and oversees the public service under private operation. A more familiar example of local cooperation constitute the Internet eXchange Points (IXPs), which are physical infrastructure elements letting Internet service providers (ISPs) and Content Delivery Networks (CDNs) exchange Internet traffic between their networks (Autonomous Systems). The switching infrastructure is built and managed as a CPR according to Fig.4, but the governance may range from a centralized $a$ to a participatory $C N$ model. IXPs and CNs are quite equivalent, the main difference being that IXPs connect larger entities only (wholesale) and CNs focus on individuals and households (retail). However, the difference blurs as $\mathrm{CNs}$ grow bigger. Two such examples are guifi.net, which serves both as a $\mathrm{CN}$ and a de-facto regional IXP, and Ninux, which acts like a country IXP of diverse city and regional networks, and is connected to the Rome IXP (Namex).

\section{E. CNs as open access network instances: the commons model}

CNs differ from other models in that crowdsourcing is practiced at all layers. Cooperative models can be a viable way to deploy infrastructure, particularly when such infrastructure cannot be built efficiently by a single entity, or duplicated and left to competition. However, cooperation requires coordination, which, when not done properly, may lead to failure. CNs are examples of 'commons' managed as common property, a collective good, also known as a common-pool resource (CPR) [15].

This is a traditional and recognized governance model for shared resource systems such as irrigation systems or fishing grounds. The participants must accept the rules to join the network and must contribute the required infrastructure to do so (routers, links, and servers). Yet, they retain the ownership of hardware they have contributed and the right to withdraw. As a result, the infrastructure is shared and managed collectively. Multiple service providers can benefit from that network infrastructure CPR to provide and compete for a range services.

In the light of the commons model, CNs embody key principles [2]:
Non-discriminatory and open access. The access is nondiscriminatory because any pricing, when practiced, is determined using a cooperative, rather than competitive, model. Typically this results in a cost-oriented model ( $v s$. marketoriented) applying the fair-trade principle for labor pricing [16]. It is open because everybody has the right to join the infrastructure.

Open participation. Everybody has the right to join the community. According to roles and interests, several main groups could be identified as stakeholders: i) volunteers interested in aspects such as neutrality, privacy, independence, creativity, innovation, DIY, or protection of consumers rights; ii) commercial entities interested in aspects such as demand, service supply, and stability of operation; iii) end users (i.e., customers), interested in network access and service consumption; and iv) public agencies (local or national), interested in regulating the participation of society and the usage of public space, and even in satisfying their own telecommunication needs. Preserving a balance among these or other stakeholders is desirable, as every group has natural attributions that should not be delegated or undertaken by any other. It is important to clarify that not all stakeholders are present in all CNs. For instance, many CNs object to the participation of commercial entities as this is against their vision and philosophy (e.g., B4RN).

As a rule, cooperation at the network deployment and operation level is crucial, i.e., contributing and deploying network infrastructure to be used as a "commons", but competition in the service provision is encouraged, i.e., each participant provides their own services and customers can choose among them, to avoid monopoly situations.

Comparing the $\mathrm{CN}$ commons model with the more general model for open access networks in Fig. 4:

- the CPR (i.e., participants of the network, legal entity) replaces the PIP and NP actors;

- the CPR offers access to private service providers (SPs) but also provides community services (CSs).

An example of the commons model in action is provided by the guifi.net $\mathrm{CN}$. The network employs cost sharing and compensation mechanisms in order to facilitate the participation of commercial SPs and operators in the CN. They deliver their services through the network infrastructure and receive payment from their customers. At the same time, they can contribute infrastructure and invest money to the CPR or compensate the network for using it [17].

Despite the attractive features of the commons model in terms of openness, it complicates considerably the sustainability question for CNs. The economical dimension is one aspect of the problem. CNs need to secure the active participation of all stakeholders in ways that ensure the continuous funding of their activities. This also involves determining acceptable ways of co-existence with commercial service providers and coping with challenges of both technical and regulatory flavor (ref. section VII). On the other hand, CNs need to stand up to the expectations they have raised and serve all those social/ethical/cultural values that serve as participation motives for their members. In the next section, we detail we enumerate 
the variety of such motives, which demonstrate most clearly the social/cultural implications of the sustainability issue for $\mathrm{CNs}$, beyond the purely economical aspects.

\section{CN STAKEHOLDERS AND THEIR MOTIVES}

Sustainability is a multifaceted concept used to study a variety of systems such as technical, biological and sociocultural ones. Its precise definition depends on the system of interest. In general, the sustainability challenge consists in understanding the way that a system can smoothly operate in the present and develop in the future. Hence, sustainability is not a specific goal per se but a continuous process to reach a goal. Although, originally the term was used in an environmental context (United Nations World Commission on Environment and Development (WCED) 1987), it more recently acquired broader social and economical semantics (World Summit on Social Development, 2005).

Equally broad is the context of sustainability in the case of community networks, which are by definition complex sociotechnical systems. Contrary to the commercial production communication networks, their existence per se is conditioned on the sustained and active participation of all its stakeholders, who contribute resources and generate value for it. Therefore, a sustainable network should first of all ensure that all these actors, primarily end users, but also commercial service providers and public organizations when they are present, have proper commitments and incentives to contribute to the network. This is not a trivial task since the participation of each actor is driven by different types of motives and aspirations, including economical, socio-cultural, and political ones. Hence, the network needs to put in place mechanisms, limits and incentive mechanisms to properly address these aspirations, as in any commons regime [15].

The success of the $\mathrm{CN}$ to attract a critical mass of actors also determines the funding alternatives of a $\mathrm{CN}$. A sustainable funding model, which will ensure the network capability to cover its deployment and maintenance expenses, is a crucial parameter for its long-term viability.

We review the practices of different $\mathrm{CNs}$ with respect to funding in section IV. In the remainder of this section, we describe the broadly varying motives met across and within the different actors in a $\mathrm{CN}$. Then, in section V, we describe how different $\mathrm{CNs}$ respond to these motives.

\section{A. Volunteers}

In the context of CNs, volunteers are the people who initiate the $\mathrm{CN}$ project. More often than not, (a subset of) these people take an active role in the network expansion, either through helping with the technical matters and/or organizing informational and training events for potential participants [18].

The volunteer groups usually comprise of people that cumulatively possess knowledge and expertise over a wide set of areas, including technical, legal, and finance matters [19]: technology enthusiasts, radio amateurs, hackers, (social media) activists, and academics. It is not uncommon for volunteers to create a legal entity (Fig. 5) to represent the network to third parties (i.e., government, third party organizations, companies,

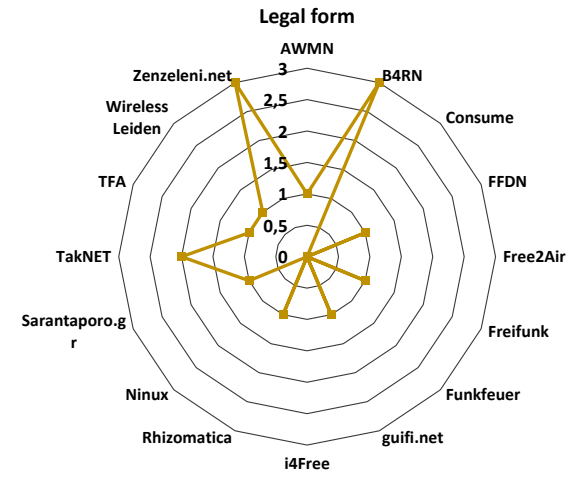

Fig. 5: Radar chart with legal forms found in CNs. CN legal forms. 0: None, 1: organization (NPO, Foundation), 2: social entrepreneur, 3: operator, ISP.

Internet Service Providers (ISPs)). This lets them have a voice and interface with third parties on legal and regulatory matters, but also get involved in financial transactions (e.g., collecting user subscriptions, fund raising, purchase of equipment).

Their motives have a strong bias towards political and sociocultural values and ideals, which is not met in any of the other three stakeholder groups. Experimentation with technology, open software and do-it-yourself (DIY) tools, sensitivity to privacy and network neutrality, the desire to bridge the digital divide, but also commitment to the community spirit and social movement, participatory governance and decision-making, and protection of consumers' rights, count as primary reasons for their involvement in $\mathrm{CN}$ initiatives. Economic motivations are much rarer; on the contrary, the members of the volunteers' groups usually end up investing a lot of personal effort, time, and money to the $\mathrm{CN}$ initiative, without direct financial return of any kind. More specifically:

1) Socio-Economic motives: Socio-cultural motives often stand behind the original conception and deployment of CNs.

Bridging the digital divide: The right to (broadband) connectivity is a matter of equal opportunities in the contemporary digital society; and digital illiteracy puts at disadvantage populations deprived of it. The launch of $\mathrm{CN}$ initiatives has many times been the response to poor or non-existent access to the Internet and Information and Communication Technology (ICT) services. This is typically the case with remote, sparsely populated rural areas, where commercial operators are reluctant to invest on fixed broadband infrastructure because they do not deem this cost-efficient.

The initial volunteers' group typically consists of local residents suffering from the digital divide (as the case is with the B4RN [11] and guifi networks [13]). However, help may also come from outside the local community. In the case of the Sarantaporo.gr network, in Greece, the CN came out of the efforts of a small group of people living in Athens and abroad, with origins from the Sarantaporo area, by the time that no broadband access alternative was available there. The 
Technology for All (TFA) Wireless Network in US got strong support by the Rice university, in order to provide Internet access to low-income communities, coupled with access to education, employment offers etc. [20].Likewise, the i4Free network in an island with poor Internet connectivity close to the town of Nafpaktos, in Greece, started from the initiative of a German engineer and professor. He created a small network at his own expenses so that locals could have access to ICT services [13], [11], [21]. Motivated by similar reasons, Peter Bloom founded Rhizomatica to promote mobile-phone based services in the rural area of Oaxaca, Mexico [58].

Economic incentives: these are in a sense relevant whenever a $\mathrm{CN}$ is set up in pursuit of cheaper (affordable) Internet access. In these cases, the underlying idea is how to expand coverage of the service, ensure its sustainability and sovereignty from commercial decisions, and save money with $\mathrm{CNs}$ compared to commercial alternatives rather than how to make money out of the $\mathrm{CN}$ initiative.

Therefore, in remote, sparsely populated areas, such as the rural areas addressed by the B4RN initiative, the competing alternatives, where they exist, such as satellite or cellular, are typically more expensive and of lower quality. B4RN was conceived also as a way to offer better connections at more affordable prices than its competitors, again in areas where these exist.

Another case, this time in urban environment, is the Consume network in East London, UK, one of the very first $\mathrm{CN}$ initiatives in Europe. James Stevens ran a technology incubation business offering web, live streaming and video distribution services through a leased optic fiber connection. He came up with the idea to connect buildings through wireless mesh links as a way to bypass the expensive license costs and regulatory constraints related to expanding the fiber communication across the buildings.

2) Political motives: Political causes often serve as driving forces for the groups that lead $\mathrm{CN}$ initiatives. Such causes often prove to be strong enough to fuel these groups' active involvement with the $\mathrm{CN}$ despite the effort, time and money this requires. They include:

Openness, net neutrality, and privacy: These highly controversial issues have served as primary motivations for $\mathrm{CN}$ initiatives. The principle of net neutrality dictates that traffic within the network should be treated in an equal manner independently of the type of content or the source. The data communicated across the network is not subject to discrimination.

A characteristic example of principles underlying the $\mathrm{CN}$ initiatives is found in the community license by the guifi.net Foundation, the volunteers' group that has developed and still operates the guifi CN, in Catalonia, Spain [22], [23], [24]:

- Freedom to use the network, as long as the other users, the contents, and the network itself are respected.

- Freedom to learn the working details of network elements and the network as a whole.

- Freedom to disseminate the knowledge and the spirit of the network.

- Freedom to offer services and contents.
Moreover, volunteers are often interested in accessing ICT services without having to compromise their privacy. This applies for technology enthusiasts, activists and users in general that wish to protect their private content. CNs such as the French FFDN and the German Freifunk declare privacy/anonymity and net neutrality as integral parts of their manifesto and incorporate them in their fundamental operation principles.

Autonomy and alternative communication models: These are common motives for the original deployment and subsequent operation of CNs [9], especially in urban areas, where the digital divide threat is much less pronounced. Community networks such as Consume ${ }^{45}$ and Free2Air ${ }^{67}$ started out representing alternative approaches to the commercial Internet provision, aiming at higher freedom and control over personal communications. In other cases, such as guifi.net, which started as an attempt to bridge the digital divide, such political purposes emerged as an equally strong motivating factor, especially when the number of network connectivity alternatives increased. In the case of Rhizomatica, the initiative was launched to serve two purposes: bridge the digital divide in areas without alternative telecom solutions, and create a more affordable telecommunications network in areas that such alternatives existed.

3) Socio-cultural motives: Socio-cultural motives often stand behind the original conception and deployment of CNs. Among the main ones count:

Experimentation with technology and DIY culture: Several initiatives are driven by hackers, technology enthusiasts, and academics who enjoy experimenting with network and radio technologies. The involvement within such a community presents them with a unique opportunity to further enhance their technical knowledge and practice it over real networks.

The AWMN, Ninux, and Freifunk CNs were initiated and are still run by network technicians and computer enthusiasts. As such, they have been characterized by a culture of experimentation and improvisation. AWMN and Ninux, in particular are used by their volunteers as testbeds for manufacturing equipment (antennas, feeders) and experimenting with routing protocols and applications. This is evidenced also in the impressive number of native applications and services that were developed for AWMN, without need for public Internet connectivity, including games, libraries, network monitoring tools, DNS solutions, and experimental platforms. Notably, neither AWMN nor Ninux, whose initials stand for "No Internet, Network Under eXperiment", nominally provide Internet access.

The TFA project was created with a combination of societal and technical objectives. Apart from empowering the local community with access to technology, the network provides an excellent opportunity of creating and carrying out research on a three-layered wireless network platform, serving as a real testbed.

Community spirit and altruism: Altruism, often coupled with a strong commitment to community ideals serve as

\footnotetext{
${ }^{4}$ http://consume.net/

${ }^{5}$ http://wiki.p2pfoundation.net/Consume

${ }^{6}$ http://www.free2air.org/

${ }^{7}$ http://wiki.p2pfoundation.net/Free2Air
} 
important motivations for the active involvement of volunteers' groups in CNs.

Both are strongly evidenced in the B4RN, Sarantaporo.gr and i4Free $\mathrm{CN}$ initiatives. Community activists have been among the leading figures in B4RN and have set it up as a community benefit society which can never be bought by a commercial operator and its profits can only be distributed to the community. Likewise, the Sarantaporo.gr non-profit organization involves people who are activists in the area of commons and supporters of community ideals. They place a lot of emphasis on cultivating these ideals in the residents of the area with parallel activities and social events. Finally, the leading figure behind the i4Free $\mathrm{CN}$, identifies himself as a warm fan of community life and ideals. He has spent enormous amounts of time trying to build a community around the $\mathrm{CN}$ through training and educational events, even without much success as he admits [11].

\section{B. Active participants}

Even broader is the variety of reasons for the involvement of citizens in a community network. Decisive for many of them is the expectation of available and abundant local connectivity anywhere is needed. Furthermore there is the expectation of cheaper, or even free, Internet access and other services provided by commercial entities. For others, the $\mathrm{CN}$ represents a perfect opportunity to acquire new knowledge and experiment with technologies, and/or socialize and become part of a bigger community. Activism in favor of higher autonomy and data privacy are also evidenced as user participation motives, albeit to a smaller extent than in volunteer groups.

Their levels of participation typical vary a lot within a $\mathrm{CN}$. Some of them are highly active participating in events organized by volunteers or other types of collective activities, sharing their technical experience, developing applications and devoting personal time and efforts to the $\mathrm{CN}$. On the other extreme, a number of users that tends to be the majority in most CNs, set up a node and use the $\mathrm{CN}$ to get Internet access or access to local services without further contributing to the activities of the community. However, the presence of even these passive users can benefit the network to the extent that others can join the $\mathrm{CN}$ through their nodes.

The $\mathrm{CN}$ users may contribute a connectivity fee for being part of the $\mathrm{CN}$ or not. These fees serve to pay the necessary costs to upgrade or maintain the $\mathrm{CN}$ infrastructure. Depending on whether they receive some service over the $\mathrm{CN}$, they may pay a consumption fee and maintain a contributor, shareholder or customer relationship with the $\mathrm{CN}$, directly or indirectly through paying service fees to a commercial service provider acting as intermediary and value-added reseller.

1) Socio-Economic motives: Users often expect benefits of economic nature from their participation in a $\mathrm{CN}$, both direct and indirect.

Direct economic benefits: The most usual one is local connectivity or Internet access that is not offered by other providers, or at lower cost than alternative solutions, offered by commercial telecom operators (Table I-A2). A characteristic example to this end is Rhizomatica, which has managed to reduce costs by $98 \%$ on international (U.S.) calls and $66 \%$ on cellphone calls.

In general, Internet connectivity is either provided by the $\mathrm{CN}$ itself, which takes on the role of an alternative Internet service provider (e.g., B4RN, Sarantaporo.gr); as an addon service over the $\mathrm{CN}$ by a third party (e.g., guifi.net, Rhizomatica); or by $\mathrm{CN}$ members who pro bono share their access with other peers (e.g., guifi.net, AWMN).

The collective efforts of the $\mathrm{CN}$ participants is often fundamental for expanding the coverage of the network or lowering the connectivity cost. For instance, B4RN partially crowdsources the cost and effort involved in deploying fiber in rural communities in Northern England. This way, it can offer fiber connectivity and Internet speed in under-served areas and at more favorable prices than alternative commercial solutions.

Notably, a locally maintained infrastructure feeds the local economy in multiple ways. First, paid jobs are created for deploying, maintaining, expanding and operating the network itself and its services (content and applications); or they become enabled by the network (telework, remote assistance, surveillance, sensing).

Then, CNs create opportunities for local investment. Locals can obtain economic benefit from investing in local infrastructures, particularly more durable fiber infrastructures, which can have good returns in terms of usage fees. At the same time, such infrastructures yield indirect economic benefits by increasing the value of households, typically the largest investment of a family.

Indirect economic benefits: Participation in a $\mathrm{CN}$ may incur additional benefits to their users. One of them relates to the growth of human capital and another to the added value that the $\mathrm{CN}$ generates for businesses and professionals participating in it. Examples from Sarantaporo.gr and AWMN show that young people (in the age of 18-35) view the CNs as a path to information about job and further education opportunities and to business activities developed around the $\mathrm{CN}$ [11]. Moreover, in remote rural areas, network access and Internet connectivity can enable professionals to search better markets for their products and cheaper suppliers for their materials (e.g., farmers) and small business owners to join the network in the anticipation that visitors appreciate the Internet connectivity feature when choosing where to go (e.g., Sarantaporo.gr). Underserved communities in terms of connectivity tend to suffer from fragility or lack of other critical infrastructures. The deployment of networking infrastructures creates economies of sharing and bundling, such as improvements in electrification, with the introduction of solar panels, that for instance can enable or improve the quality of night-time lighting and food preservation, which in turn may create economic benefits from trading of these products.

2) Political motives: As seen in section III-A2, many CNs have been initiated under aspirations of privacy, net neutrality, and alternative models of Internet connectivity provision with strong flavor of autonomy and self-organization. The ideals underlying the initial development of these CNs are often inherited by subsequent users of the $\mathrm{CN}$. However, these users tend to be a small part of the total $\mathrm{CN}$ user population. Typically, the larger the $\mathrm{CN}$ grows the harder it becomes to 
find political causes that unite the whole community behind them.

Openness, net neutrality and privacy: The aspects of privacy and neutrality have a strong role in CNs that utilize the Picopeering agreement ${ }^{8}$ as a participation/operations framework and are part of the movement for open wireless radio networks ${ }^{9}$ (e.g., Freifunk, guifi.net, Ninux, FFDN).

The Picopeering agreement is a baseline template formalizing the interaction between two network peers. It caters for a) an agreement on free exchange of data; b) an agreement on providence of open communication by publishing relevant peering information; c) no service level guarantees; d) users' formulations of use policies; and e) local amendments dependent on the will of node owners.

Autonomy and self-organization: The participation in $\mathrm{CN}$ groups cultivates feelings of autonomy and self-organization. Self organization is practised in the way new users connect to the $\mathrm{CN}$, where they have to rely on their own resources and the voluntary assistance of experienced network members. Being part of an independent network satisfies personal ideological aspirations for self-organized network and autonomous use [9]. The ability to participate in collective decision making and contribute to an alternative "commons"-based model of ICT access counts itself as a worthy experience for users with strong "commons" ideals.

3) Socio-cultural motives: A CN is a characteristic example of participatory involvement, where users dedicate their efforts and time to the network [25]. A number of services and applications combined with other activities that one way or another revolve around the $\mathrm{CN}$, offer users the opportunity to communicate, educate and entertain themselves, thus further motivating their participation in the network [8], [26].

Experimentation and training with ICT: Technology enthusiasts participate in the network for experimenting with the technology i.e., trying software they develop and modify, make network speed measurements, play with network mapping and management tools [9]. Users can acquire new skills about computer and network use, i.e., either through selfexperimentation or through training by network experts.

In CNs initiated by volunteers with technical background (e.g., AWMN, Ninux, Freifunk), the amount and type of services, applications and self-produced software increased greatly within the community. Besides a variety of network monitoring tools, users can enjoy communication services such as VoIP, online forums, mails, and instant messaging; data exchange services with servers, community clouds and file sharing systems; entertainment services with gaming applications and audio/video broadcasting tools; information and educating services with online seminars, e-learning platforms, and wikis.

Desire for social interaction: The smooth operation and development of a $\mathrm{CN}$ demands cooperation links at the network infrastructure level but also at the social level. In $\mathrm{CNs}$, participants are able to share their ideas and interests, participate in groups, interact and communicate with other

\footnotetext{
${ }^{8}$ http://www.picopeer.net/PPA-en.shtml

${ }^{9} \mathrm{https}: / /$ openwireless.org/.
}

network members just like they would in any other online or physical community. Social networking and communication tools raise great interest and remain active even when other tools and services have a drop in their utilization.

The importance of local relationships in a $\mathrm{CN}$ [27] is also evidenced in three independent studies addressing a rural village in Zambia [28], the TakNet $\mathrm{CN}$, in the rural area of northern Thailand [29], as well as Australian and Greek CNs in [9]. In this last study, $91.2 \%$ of the users stated that they enjoyed interacting with the community, $88 \%$ felt that their efforts would be returned by other community members and $80.5 \%$ expressed that the community allowed them to work with people that they could trust and share similar interests. Likewise, in the case of TakNet, much of the activity among users of the popular applications such as messaging, email, online social networks and gaming, exhibits a high degree of locality, i.e., people use Internet to interact with people within the same $\mathrm{CN}$.

Socio-psychological motives: As social motives count socially-aware mechanisms that relate to concepts such as visibility, acknowledgment, social approval, individual privileges and status. This social activity is applied within the networks' technical limits [30].

The ability to compete with other people and satisfy one's self esteem through the involvement in the community, or receive a certain type of credit by others in the community, are motives not as easy to distinguish but still present [9], [29], [28], [31] and with an impact on network growth and operation [32], [33].

\section{Private sector service providers (professionals)}

Private sector service providers form the stakeholder type that may be less involved in $\mathrm{CN}$ initiatives. The term points to companies, ISPs, small businesses or individuals, namely entities that support or use the network to provide some service and get compensated for it. These can be a) the professionals that are involved in the installation, operation and maintenance of the CPR network infrastructure, or b) the organizations that provide content or services inside the $\mathrm{CN}$. At first glance, these entities do over the $\mathrm{CN}$ what they do over any other network, i.e., provide services where there is demand for them. However, the legal provisions and conditions of running business over the $\mathrm{CN}$ may be different given the existence of a CPR infrastructure and the governance and the crowdsourced nature of it. In fact, the CPR is an enabler of small private sector providers. Since the network commons is a shared resource, that enables these small players to operate and provide services over a larger population, with the economies of scale of cooperative aggregation of CAPEX and OPEX among multiple participants, and the complementarity and opportunities of specialization among them. This also means a lower barrier or entry, with much less initial investment and less risk thanks to the cooperative, and cost oriented model, of the network commons. Therefore the network infrastructure commons becomes a critical resource for the operation and competitiveness of these local private sector service providers. Therefore the common goal would be preserving the commons to enable their specific business models. 


\begin{tabular}{|l|l|l|}
\hline CN & Legal form & Funding \\
\hline AWMN & AWMN Foundation & Members (individually) \\
\hline B4RN & Community Benefit Society & Members \\
\hline Consume & None & Central actors \\
\hline FFDN & Non-Profit Organization & Members, Local authorities, Donations \\
\hline Free2Air & Incorporated Legal Company & Members \\
\hline Freifunk & Non-Profit Organization & Members, Public Institutions \\
\hline Funkfeuer & None & Members \\
\hline guifi.net & Guifi.net Foundation & Members \\
\hline i4Free & None & Central actor \\
\hline Ninux & None & Members \\
\hline Rhizomatica & Non-Profit Organization & $\begin{array}{l}\text { Members, National and International orga- } \\
\text { nizations, Donations }\end{array}$ \\
\hline Sarantaporo.gr & Non-Profit Organization & Members, European Union, Donations \\
\hline TakNET & Social enterprise - Net2home & $\begin{array}{l}\text { Members, Private Insitutions, THNIC Foun- } \\
\text { dation, European Union }\end{array}$ \\
\hline TFA & Non-Profit Organization & $\begin{array}{l}\text { Members, Foundations, Public Institutions, } \\
\text { Donations }\end{array}$ \\
\hline Wireless Leiden & Non-Profit Organization & Members, Public/Private Institutions \\
\hline Zenzeleni.net & Formal Network/Telecom Operator & Members, Public Institutions \\
\hline
\end{tabular}

TABLE III: CN specific organizational aspects.

The incentives for the participation of private sector service providers in the network are almost always economic. These actors are interested in profit. The $\mathrm{CN}$ provides them with access to potential customers who would otherwise be unreachable. The implementation of their commercial activities depends on the organizational nature of the CN. Guifi.net has set up a framework that enables the participation of private sector in its $\mathrm{CN}$, including maintainers, installers, ISP providers, VoIP providers (Table III-C). These entities may sign agreements with the guifi.net Foundation, when the service provision has to do with the sustainability of the CPR. External Over-The-Top (OTT) services, such as Internet VOIP, Video, content providers are left outside. In Rhizomatica, ISPs and VOIP providers are key partners of the organization. Rhizomatica provides the Radio Access Network through which the service providers reach the local communities and their CN users. Network, such as TFA or guifi.net, include a self-sustainable business model where ISPs provide Internet access over the network.

\section{Public agencies}

Public agencies have the natural role of regulating the public space, either for service provision, occupation of public spectrum, public land, but also supporting local development and ensuring access rights to public information and services. Public agencies have a responsibility to regulate the deployment and service provision of CNs, as with any other entity performing these activities. Furthermore, they may cooperate with a $\mathrm{CN}$ when the mission of both align. They may contribute to its deployment and growth through funding the initiative, sponsoring network equipment, consuming $\mathrm{CN}$ services, facilitating its expansion and growth or by permitting the use of public space and resources by a CN. In Catalonia, the Foundation operating guifi.net has developed the Universal format [34], a template municipal ordinance, that allows municipalities to regulate public, commercial and community entities to deploy shared infrastructures in public space. Under these principles, several local authorities have allowed guifi.net groups to dig public space and lay down fiber for expanding the network. In several German cities, Freifunk is given the permission to set up antennas and equipment in the roof top of churches, Town Halls, or other public buildings.

Quite often other types of public agencies get involved in the network. Sarantaporo.gr has received network equipment for the initial deployment by the Greek Foundation for opensource software and Internet connectivity from the regional University of Applied Sciences. TakNet received financial support from the Thai Network Information Centre Foundation and initial equipment donation and support from the Network Startup Resource Centre.

Depending on their level of participation public agencies can sign collaboration agreements with the legal entity of the $\mathrm{CN}$ and contribute economic or infrastructure resources with or without compensation.

1) Socio-economic motives: The participation of public agencies in a $\mathrm{CN}$ initiative can also have an economic motivation. In the case of guifi.net public agencies can fund the network expansion through purchase of equipment in return for complimentary added value services over the CN. Public agencies may be interested in the added value of purchasing connectivity services from a CPR infrastructure, as while being competitive in price, can amplify the spill-over effects in the local economy, and contribute to socio-economic development. However, public entities may also be tempted to put obstacles as a result of the influence and pressure of traditional large telecom companies, with more taxation than large telecom or Internet players that may enjoy unfair tax benefits. 


\begin{tabular}{|l|l|}
\hline Services & Private sector providers \\
\hline \multirow{3}{*}{ Internet Service Provider (ISP) } & $\begin{array}{l}\text { Adit Slu, Ballus Informatica, Capa8, Cittec, Delanit, Del-Internet Telecom, Ebrecom, } \\
\text { Emporda Wifi - Guifinet a l'Alt Emporda, Girona Fibra, Goufone, Indaleccius Broad- } \\
\text { casting, Pangea.org, Priona.net, S.G. Electronics, Steitec-Servei Tècnic d'Electronica i } \\
\text { Telecomunicacions, Ticae, Xartic }\end{array}$ \\
\hline \multirow{3}{*}{ Mobile Provider } & $\begin{array}{l}\text { Ballus Informatica, Capa8, Cittec, Delanit, Ebrecom, Emporda Wifi - Guifi.net al Alt } \\
\text { Emporda, Girona Fibra, Goufone, Indaleccius Broadcasting, Priona.net, S.G.Electronics, } \\
\text { Ticae }\end{array}$ \\
\hline \multirow{2}{*}{ Surveillance } & $\begin{array}{l}\text { Ballus Informatica S.L., Capa8, Delanit, Ebrecom, Girona Fibra, Goufone, Matwifi, } \\
\text { S.G. Electronics, Ticae }\end{array}$ \\
\hline Telephony (VoIP) Provider & $\begin{array}{l}\text { Ballus Informatica, Capa8, Cittec, Delanit, Del-Internet Telecom, Ebrecom, Emporda } \\
\text { Wifi - Guifinet a l'Alt Emporda, Girona Fibra, Goufone, Indaleccius Broadcasting, } \\
\text { Matwifi, Priona.net, S.G. Electronics, Ticae }\end{array}$ \\
\hline Agreement types & Delanit, Del-Internet Telecom, Indaleccius Broadcasting, Priona.net \\
\hline Economic Activity Agreement & Service providers \\
& $\begin{array}{l}\text { Adit Slu, Asociacion SevillaGuifi, Associacio Guifinet la Bisbal d'Emporda, Ballus } \\
\text { Informatica, Capa8, Cittec, Delanit, Del-Internet Telecom, Ebrecom, Emporda Wifi - } \\
\text { Guifi.net al Alt Emporda, Girona Fibra, Goufone, Indaleccius Broadcasting, Ion Alejos } \\
\text { Garizabal, Maider Likona, Matwifi, Pangea.org, Priona.net, S.G.Electronics, Steitec- } \\
\text { Servei Tecnin d'Electronica I Telecomunicacions, Ticae, Xartic }\end{array}$ \\
\hline Volunteer Agreement & Cittec, Girona Fibra, Matwifi \\
\hline
\end{tabular}

TABLE IV: Private sector service providers in guifi.net and the services they provide.

2) Political motives: The participation of public agencies in a $\mathrm{CN}$ often comes as a result of high-level policies against the digital divide, to increase the offer or lower the costs of local connectivity, and in favor of equal opportunities in the digital economy and society.

3) Socio-cultural motives: Public agencies may also support $\mathrm{CNs}$ because they acknowledge their long-term potential to strengthen the community links, raise awareness for issues concerning the local societies and favor the engagement of citizens with the commons. On the polar opposite and more opportunistic note, local administrations (such as municipalities) can advertise the provision of network services as a political achievement that increases their re-election chances.

\section{ECONOMIC SUSTAINABILITY OF CNS: PRACTICE AND THEORETICAL MODELS}

$\mathrm{CNs}$ tend to use one or more of the following ways (see also Table III-B3) to fund their activities [35]:

\section{A. Member subscriptions and contributions in kind}

This is the most common funding source for CNs. In this case, the members of the $\mathrm{CN}$ contribute network equipment and time/effort to the network growth and maintenance. In the case of the BARN network, which provides fiber connectivity, members even contribute digging effort. In most cases, the $\mathrm{CN}$ users pay a monthly/annual subscription fee for the $\mathrm{CN}$ needs. Several CNs such as AWMN in Greece, Ninux.net in Italy, BARN in UK, and Freifunk.net in Germany, have managed to scale significantly this way.

Despite its simplicity, the model has several variations. Subscriptions may be mandatory or voluntary; or they may serve as a prerequisite for participation in decision-making bodies and award of voting rights. In the case of the Sarantaporo.gr, it is villages under the network coverage, rather than individual $\mathrm{CN}$ users, that are charged with a fee. How each village will split the cost between local users is left to the the $\mathrm{CN}$ participants in that specific village to define.

What the $\mathrm{CN}$ users get in return for their subscriptions is closely related to the way the $\mathrm{CN}$ organizes and positions itself in the telecommunications arena. For example, B4RN operates as a community benefit society, which provides Internet service to its subscribers. The subscription model is composed of a connectivity fee and different service fees for different types of users. On a similar note, Zenzeleni.net operates as a cooperative telecommunications operator providing voice and data services to its customers. TakNet has developed a social enterprise called Net2Home. Users have to pay monthly fees that are used for covering fiber (to the network operator), maintenance, equipment installation, technical online support, network management and monitoring costs. Rhizomatica helps communities in Mexico build their networks, receiving a flat rate for equipment installation and community member training as well as a percentage of monthly subscription fees for advisory and technical services. TFA practices a selfsustainable business model, where the network relies on ISPs to provide Internet access to its members.

Finally, but far more rarely, a $\mathrm{CN}$ may operate as a forprofit company. Some of the FFDN networks in France are commercial networks that indeed rely on policies such as standard pay-per-use contracts and added value services to customers outside the $\mathrm{CN}$. However, in contrast with traditional commercial companies that extract profit from customers and locals to compensate the investors, $\mathrm{CNs}$ reinvest the profits in the CPR infrastructure.

\section{B. Donations from supporters}

Community Networks are often financed through crowdfunding projects or direct, regular or one-time, donations.

In some $\mathrm{CNs}$, citizens can invest in the infrastructure. This may happen for a specific reason such as crowdfunding the 
construction of a new link or the improvement of an existing one that affects the user (typical in guifi.net); or in more statutory manner, through the purchase of community shares, to expand the local network or even the home access (in B4RN). These investments can generate tax returns (guifi.net Foundation or $\mathrm{B} 4 \mathrm{RN}$ ). In $\mathrm{B} 4 \mathrm{RN}$ this investment also generates $(3 \%)$ interest after the third year.

External donors contribute funds in $\mathrm{CNs}$ in developing areas such as in Zenzeleni (ZA), and Rhizomatica.But also in Europe, Freifunk.net offers a good example of attracting such support through a dedicated non-profit organization, which is meant to require as little as possible (voluntary) effort. For this reason, it has a relatively small number of regular members and a large circle of supporting members, which can all participate in the annual general meeting. The membership includes a fee of either 60 EUR (or more) per year to the Association's account as annual sponsor membership, or the monthly equivalent of 5 EUR (or more) for sustaining membership.

Overall, this funding source typically complements other funding sources such as the members' subscription fees since it rarely suffices to cover the CN's funding needs.

\section{Support from public agencies and institutions}

There are cases, where $\mathrm{CN}$ initiatives have got generous support from public funds (cash or in kind). Municipalities and local authorities emerge as main actors in this respect. The synergy of commons/public service with civil society/municipality can limit the survival concerns of CNs as far as one finds sustainable models that motivate their cooperation [36], [37],[38].

One such case is the Sarantaporo.gr $\mathrm{CN}$, which set up its first nodes with hardware and equipment received from the Greek Free/Open source Software Society (GFOSS); and, later, expanded the $\mathrm{CN}$ through funding by the CONFINE project [39], funded by the European Commission. Likewise, much of the TFA start up funding came from foundations, grants and bank loans. Likewise, in the case of Freifunk, the support from public authorities was expressed through making available public buildings such as churches or Town Halls for placing and storing the network's equipment (e.g., antennas).

Sometimes, the support may be expressed in more indirect, yet equally significant, ways such as giving proper attention to $\mathrm{CNs}$ in regulatory actions. The guifi.net Foundation has developed a cooperative infrastructure sharing model (the Universal deployment model) that develops over the Directive 2014/61/CE on broadband cost reduction of the $\mathrm{EU}^{10}$ and the infrastructure sharing concept of the ITU ${ }^{11}$. The model prescribes how municipalities and counties can regulate the use of public space by private, government and civil society in a sustainable manner [34].

Another instance of such support is the award of code powers to $\mathrm{B} 4 \mathrm{RN}$ in $\mathrm{UK}$ by Ofcom, the national regulator. Such codes, also possessed by traditional telcos, allow network builders to build and maintain infrastructure on streets without

\footnotetext{
${ }^{10}$ https://ec.europa.eu/digital-single-market/en/news/ factsheets-directive-201461ce-broadband-cost-reduction

${ }^{11}$ https://www.itu.int/ITU-D/treg/publications/Trends08_exec_A5-e.pdf
}

having to obtain a specific street works license. This way, they become immune to town and country planning legislation, and can apply to the courts to obtain rights to execute works on private land if agreement cannot be reached with landowners. The possession of code powers has enormously cut down on the infrastructure deployment cost of the B4RN CN, both in terms of compensations for traversing private land and bureaucracy.

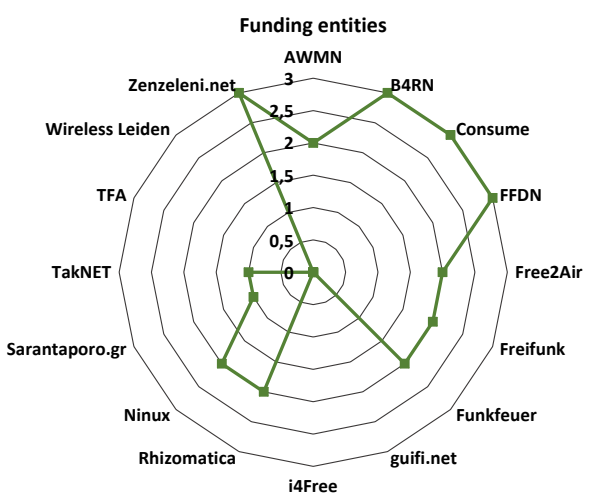

Fig. 6: Radar chart with $\mathrm{CN}$ funding entities in a 0-3 scale. CN funding sources. 0: mainly private entities' involvement, 1: mainly public agencies' involvement, small scale member contribution 2: mainly member contribution (donations, non regular fees), 3: member contribution only (regular fees).

\section{Funding from third-party for-profit actors using the infras- tructure}

In the case of guifi.net, $\mathrm{CNs}$ have come up with unique innovative models combining voluntary and professional services into a commons-based approach. Commercial service providers offer services over the $\mathrm{CN}$ and charge the $\mathrm{CN}$ users as typical customers, but also subsidize the $\mathrm{CN}$ growth and maintenance subscribing to the commons policies. This way, the $\mathrm{CN}$ maintains its non-profit orientation and pursues its sustainability through synergies with entities undertaking commercial for-profit activities [17].

When assessing the strengths and weaknesses of the four categories of funding sources, the following remarks are due:

- Some sources (i.e., donations, voluntary contributions etc.) are one way or another not guaranteed and they make long-term strategic planning difficult. They could also lead to disagreements and conflicts between $\mathrm{CN}$ members concerning their distribution inside the network, especially if there are not well-defined decision-making processes.

- Unless something dramatically changes on the regulation side, the support of public authorities for CNs cannot be taken for granted. BARN is one $\mathrm{CN}$ instance that tried to access national funding without success (their bid for the funding was eventually withdrawn). In the case of guifi.net, the municipality of Barcelona is not willing to 
provide the $\mathrm{CN}$ with access to the city wi-fi and fiber infrastructure. In general, $\mathrm{CNs}$ tend to view access to local, national or European funds too difficult as well as demanding, uncertain, and bureaucratic.

- The dominant view across $\mathrm{CN}$ initiatives is that the funding from own resources is the most reliable and favorable option. B4RN and Freifunk, two of the three networks in Europe that have managed to scale in the order of tens of thousands of nodes, have followed this approach.

- Trying to put commercial service providers in the loop while preserving the $\mathrm{CN}$ ideals, as guifi.net does, definitely represents an innovative approach. The success it experiences in the case of the guifi network renders it a valid funding model alternative.

Interestingly, only guifi.net so far has managed to involve in its funding model all possible actors (end users/members, private sector and public authorities). Striking the right balance between the roles and contribution modes of these three parts may prove the key towards the economic sustainability of $\mathrm{CN}$ initiatives.

Fig. 6 summarizes the funding dependencies of the $16 \mathrm{CNs}$ on different sources.

\section{E. Theoretical models of CN economic sustainability}

The economic sustainability of $\mathrm{CNs}$ has also been the subject of theoretical studies. The impact of pricing strategies, network coverage and user preferences on the $\mathrm{CN}$ sustainable operation is mainly explored therein with game-theoretic tools.

Maybe the first study of pricing issues in CNs is [40]. It is assumed that the end users have the alternative of a commercial licensed based operator and the price they are willing to pay for $\mathrm{CN}$ connectivity grows with the coverage the $\mathrm{CN}$ achieves. Hence, the $\mathrm{CN}$ coverage and revenue evolve over time and, depending on the price and initial CN coverage, the result may be a competitive $\mathrm{CN}$ with high coverage or one that dies out. The analysis identifies the pricing strategies of the two operators at Nash equilibrium and the benefit resulting for end users due to the competition between them.

In [41], the model in [40] is elaborated further to address individual user mobility patterns, and different types of network nodes to which users associate with different frequencies. The assumption is that the $\mathrm{CNO}$ possesses complete or partial information about the way users move and their differentiated perception about the network' coverage so that it can optimally determine the subscription fees over a number of periods ahead in time.

Afrasiabi and Guerin in [42] also propose a simple utility function to model the users' varying propensity to roam and the emphasis they assign on network coverage. However, and contrary to [40], their model also accounts for negative externalities: as the users of the network grow, the roaming traffic load increases and limits what is available to them, as either home or roaming users. They find that a fixed pricing policy generally fails to align the total welfare, i.e., the sum of the operator's revenue and the users' utilities, with the profit of the operator, exhibiting less flexibility than discriminatory pricing and usage-based pricing strategies, which charge the user differently if she is at home or roaming.

Finally, a study that is more directly inspired by the FON service model [43] is presented in [44]. Three types of $\mathrm{CN}$ user memberships are identified therein, depending on whether users own an AP or not and whether they share and access the CN APs free of charge ("Linus" users) or for a small fee ("Bill" users). The CN users play a two-stage dynamic game involving two different decisions at different time scales: they select membership types over time intervals in the order of months and how aggressively to access the shared radio channel over time intervals in the order of a few minutes. The authors analyze the Subgame Perfect Equilibrium strategies and study when these are realized by best-response strategies.

\section{InCEntive MeChanisms in CNS}

To ensure a sustainable presence, $\mathrm{CNs}$ have put in place diverse incentive mechanisms. As with other types of commons [15], the main purpose of these mechanisms is to limit, encourage and fuel the original motives for participation of all types of actors. They also aim to prevent phenomena and conditions that might weaken the original motivation of actors. Such phenomena include mainly:

Free riding and selfish behaviors: many users are solely interested in enjoying network connectivity without themselves contributing adequate or any resources to the $\mathrm{CN}$. Such behaviors can easily lead to the depletion of network resources and $\mathrm{CN}$ degradation. Mechanisms for organizing and ensuring users sustained contributions and distributing effort across them are of significant importance.

Unclear CN legal status: $\mathrm{CN}$ actors (users or private sector entities) may be deterred from joining the network and participating in its activities if its legal status is not clear. Well established operational and participation rules can alleviate such effects.

In what follows, we review incentive mechanisms that are either in place in different $\mathrm{CNs}$ or have been proposed, without (yet) finding a path to implementation, in the literature. In the latter context, we also review mechanisms that have been proposed for similar systems such as wireless ad-hoc networks, P2P systems, and virtual online communities. These systems display inherent structural similarities with CNs in that they also depend on the collective effort and cooperation of their participants to fulfill their tasks: forward and route data in wireless ad hoc networks, disseminate files and other data in P2P systems, share effort and data in virtual online communities.

The different incentive mechanisms aiming to motivate the participation in $\mathrm{CNs}$ and strengthen their sustainability are grouped into six categories (Fig. 7).

\section{A. Enforcing fairness in users' contributions and interactions}

Despite the direct threat that free riding phenomena pose to the network's long-term sustainability, actual prevention countermeasures are not that widespread in most CNs, with the notable exception of guifi.net [2]. Interestingly, a quite 


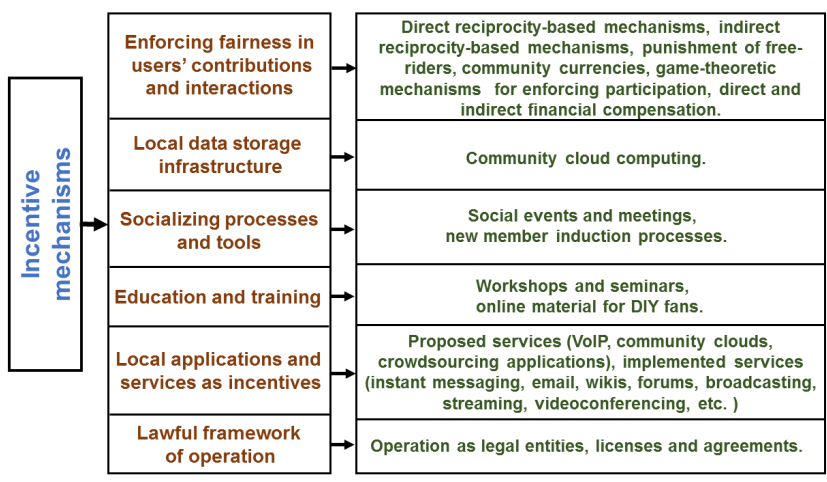

Fig. 7: Categories of incentive mechanisms used in CNs.

broad range of solutions have been proposed in the literature, either in the specific context of CNs or that of similar systems (wireless ad-hoc, P2P, and online virtual communities) [45], [46].

1) Direct reciprocity-based mechanisms: Reciprocity is a broad term that incorporates the notion of human cooperation in different interaction scenarios [47]. Direct reciprocity keeps records of the interaction of two specific individuals so that the accounts are settled between those two. The "tit-for-tat" manner of connecting to wireless CNs is quite common practice between their members. For a node to connect to a $\mathrm{CN}$, there must be another node to which the connection is directed. In many cases, the reciprocal sharing obligations stemming from the participation in the $\mathrm{CN}$, are explicitly described in licenses such as the Wireless Commons License (WCL) [2] ${ }^{12}$ defined in terms of neutrality and general reciprocation.

Direct reciprocity mechanisms can be described in various contexts such as in sharing network connectivity or storage and computing resources. The compensation tables in guifi.net is a key resource to ensure the economic sustainability of the network, ensuring a cooperative and cost-oriented model to share the recurring costs and balance investment, maintenance and consumption [17].

In terms of proposals, connectivity sharing is the objective studied in [48]. A reciprocity algorithm, coupled with the P2PWNC protocol in [49], keeps account of the services each participant provides and consumes via technical receipts. This way, it keeps a balance between the amount of traffic users transfer and that they relay on behalf of others. The model considers the provision of Internet access through the APs of a wireless CN. Participants are divided into teams that manage their own APs and consume/contribute traffic of/to another AP.

Reciprocity-based mechanisms for sharing storage and computing resources are reported in [50], [51] and [52]. In [50] and [51], the reciprocity-based mechanism is implemented over a Community Cloud made out of shared computational resources of the network members and is based on records of participants' efforts. Results indicate that the most suitable structure for community clouds should distinguish between ordinary nodes that possess cloud resources and super nodes that are responsible for the management of resource sharing.

${ }^{12}$ http://wiki.p2pfoundation.net/Wireless_Commons_License
In [52], mobile devices used for computing, borrow CPU slots in a reciprocal manner. It is suggested that the heterogeneity in the amount of available resources may not be beneficial for participants with large-scale resources.

2) Indirect reciprocity-based mechanisms: The concept of direct reciprocity readily expands to that of indirect reciprocity, which is essentially realized by reputation mechanisms. Indirect reciprocity does not consider two specific individuals (like direct reciprocity) but rather asymmetric random exchanges based on the reputation scores of each individual node. Key issues in building reputation mechanisms [53], involve keeping past behavior records (as node reputation is partially built over time), carefully evaluating all of the acquired information and distinguishing between old data vs recently gathered ones. Among other challenges, reputation-based systems have to face the impact of liars on peer reputation i.e., nodes giving unreliable information about other nodes. The system should be able to yield immediate response to known misbehaving nodes by drawing from past information.

The guifi.net classification of suppliers ${ }^{13}$ (professionals, volunteers) provides a public ranked list according to reputation of professionals and volunteers available for a range of tasks. The list is based on the certification of their abilities based on actual deployments or training courses.

Reputation mechanisms have been proposed for P2P systems and wireless ad-hoc networks. In [54], such a mechanism is developed to build a reputation score for P2P system participants. Each peer is described based on how much service (bandwidth, computation) it provides and consumes. Peers are encouraged to collaborate with each other and receive an increase in their reputation metrics. The mechanism successfully results in peers making coalitions that eventually work to their benefit. In a similar rationale for routing in mobile ad-hoc networks (MANETs), the reputation technique aims at isolating non-cooperative node behavior using the Confidant protocol. The tamper-proof hardware, which is embedded in nodes, keeps account of their virtual credit collected as they contribute in packet forwarding. The reputation mechanism in [55] keeps records of the collaboration activities of nodes in the MANET and builds a reputation score for each node, based on monitored collaboration data and information input from other nodes.

3) Punishment of free-riders: Free riding is a quite common problem in commons, experienced in various forms by each network type. The design of long-enduring CPR institutions [15] requires graduated sanctions for appropriators who do not respect community rules.

This implies defining the "boundaries", determined by the community license and agreements, and requires effective conflict resolution methods that may include sanctions [2]. The conflicts resolution system in guifi.net provides a systematic and clear procedure for resolution of conflicts with participants that negatively affect the common infrastructure resource, with a scale of graduated sanctions. It consists of three stages conciliation, mediation, and arbitration- all of them driven

${ }^{13}$ https://guifi.net/en/node/3671/suppliers 
by a lawyer chosen from a set of volunteers. This has been found critical to keep the infrastructure and the project itself operational.

In multi-hop wireless networks, consumption of bandwidth and energy serve as the main motivations for nodes' free riding behavior. Nodes enjoy packet forwarding of their own packets by other nodes but defer, either deterministically or probabilistically, from forwarding the packet of other nodes. Detection and punishment of suspected free-riding nodes are the two basic steps suggested for dealing with this phenomenon in the corresponding literature.

In the generic setting in [56], it is suggested that free riding should be confronted using exclusion of peers from a group as a plausible threat. Misbehaving nodes are detected through reputation protocols and excluded from the network or community. Detection of selfish behaviors of mesh routing nodes is carried out in [57] with a trust-based mechanism. The mechanism can be developed based on the combined observations of neighbor (and other) nodes of the CN such as in KDet [58]. The Catch protocol in [59], tries to limit the free riding problem in multi-hop wireless networks while preserving anonymity. The adopted technique uses anonymous messages and statistical tests to detect the selfishly behaving nodes and isolate them. It relies on the assumption that freeriding does not appear in the initial stages of the network deployment but later, as the number of peers starts to grow. The corresponding example in $\mathrm{CNs}$ reflects the fact that the initial members, i.e., volunteers, create the $\mathrm{CNs}$ based on certain principles and knowledge that are not compatible with free riding practice. Members that join the network in subsequent stages, i.e., users, are often not acquainted with these principles and the importance of complying to them.

4) Direct and indirect financial compensation: This type of mechanisms aim to support CNs' economic sustainability. Guifi.net, a representative example of this category, involves private sector actors that provide commercial services in the $\mathrm{CN}$. To this end, it has set forth additional mechanisms for compensating contributions of different stakeholders i.e., compensation system, provision of donation certificates [17].

The compensation system aims at settling imbalances between network usage and contributions (CAPEX or OPEX). It is a way for participating entities to share network costs while acquiring network resources. Private sector service providers may assume the roles of operators that contribute to the network and consume its resources, investors that only contribute, and pure operators that only consume network resources. Operators can contribute either to the deployment of the infrastructure or to its maintenance.

The provision of donation certificates that are amenable to tax deductions, is a way of acquiring indirect benefits for contributing to a commons infrastructure. Users who pay commercial service providers for service provision, can have some tax deduction benefits as well according to the Spanish legislation and regulation authorities.

Other mechanisms explored in the literature but not yet validated in $\mathrm{CNs}$ are the following.

5) Community currencies: The design of community currencies is a way to enforce reciprocity and balance the contri- butions of nodes to the network. As long as the cost/value of nodes' contribution can be quantified, community currencies can ease the exchange of a wider set of services between $\mathrm{CN}$ members and users of a $\mathrm{CN}$ and properly reward voluntary activities. At the same time, community currencies are themselves collaborative activities that increase the community spirit and strengthen the intrinsic motivations for participating in a $\mathrm{CN}$. In fact, the smooth operation of a community currency depends heavily on building trust between community members both to accept and use the corresponding currency but also to be able to provide risk-free credits that are very important for the required flow of currency. This trust is a very important asset that can play a key role in the initial birth and sustainable operation of CNs. For the same reason (existing trust and community values), the existence and operation of a $\mathrm{CN}$ eases the launch of a community currency. The development of community currencies for $\mathrm{CNs}$ is yet at an initial stage but they pose a promising mechanism that exhibits a complex bidirectional relation with $\mathrm{CNs}$ [35].

6) Other game-theoretic mechanisms for enforcing participation: Participant's motives for contributing in CNs can be enhanced by game-theoretic and mechanism design approaches. An incentive mechanism based on a Stackelberg game is provided in [60]. The objective is to stimulate user and ISP provider participation in a hypothesis of a global $\mathrm{CN}$ where the participating entities (users and ISPs) interact with an intermediate entity, i.e., the community provider or mediator.

Due to the cooperative nature of $\mathrm{CNs}$, participation of peers often needs to be combined with mutual cooperation i.e., forwarding packets, amongst them. While some works use reputation-based mechanisms there are others that prefer credit as a plausible economic incentive to sustain participation. The works in [61], [62], [63] and [64] tackle this objective in different types of systems i.e., P2P, static or mobile ad-hoc systems.

In a P2P network setting [61], the prisoner's dilemma is chosen to design incentive techniques and deal with challenges such as large populations with small lifetime, asymmetry of interest in participation and multiple peer identities. In order to enhance cooperation and avoid false identities and hijacking, the mechanism proposes to keep records of peer interaction and use them to build reputation metrics. In another approach, the work in [62] uses game theory techniques to enhance cooperation in static ad-hoc networks and suggests that the most effective incentivizing structure is one that combines actual incentive mechanisms i.e., actual credits as reputation systems or virtual currencies, with mechanisms that target players' self interest and enjoyment. A Video on Demand service on wireless ad hoc systems is the setting for the Stackelberg game presented in [65]. In order to promote cooperation among participants i.e., upload and forward data, the content provider offers them rewards which vary across actual payment, virtual credit or reputation points. A software protocol in [63] combined with a game-theoretic aspect is used to stimulate cooperation among selfish nodes in mobile ad-hoc networks. A cheat-proof and credit-based mechanism determines node rewards and costs which are utilized for 
packet forwarding and route discovery.

\section{B. Socializing processes and tools}

$\mathrm{CNs}$ have developed a great variety of mechanisms to promote participation, interaction and knowledge dissemination among $\mathrm{CN}$ members i.e., social events, meetings, new member induction process. These mechanisms serve as a "social" incentive to encourage active involvement and engage new and old members to $\mathrm{CN}$ processes and operation.

1) Social events and meetings: Large- and small-scale $\mathrm{CNs}$ organize gatherings and events to discuss not only $\mathrm{CN}$ organizational matters but also strengthen the bonds of community members through social activities. Face to face meetings are common practices. Depending on their morphology i.e., a single network or network of networks, $\mathrm{CN}$ members have meetings weekly, monthly or annually. CNs which are composed of smaller networks (guifi.net, Ninux, Freifunk), tend to have weekly or monthly face to face meeting at the local networks and an annual global meeting to get together and discuss the issues arising from the operation of the entire network. Other CNs like AMWN, schedule frequent meetings (i.e., General Assembly) when important organizational matters are up for discussion.

2) New member induction processes: Depending on the mentality and philosophy of the particular $\mathrm{CN}$, interaction with network members is a natural prerequisite for a newcomer's access to the network. The way that this interaction is later on retained, is possible to determine their individual participation level. For example in AWMN or guifi.net, new participants are urged to register and communicate with nodes of physical proximity to them. After communicating with the node owners, they are able to receive advice about the equipment they need and acquire assistance from existing members in setting up their own nodes and joining the network. Many node owners provide public contact information for others to contact them. In cases, where actual interaction with node owners is not possible or for complementary assistance, users can register to the website and post their questions in the CN's forum.

\section{Education and training practices}

Education and training of $\mathrm{CN}$ members is an important aspect of CNs, addressing their members desire for acquiring new skills and learn more about networking and radio technologies. Seminars, workshops and online manuals are the main deliverables of this line of effort, invested typically by members of the volunteers' group but also by other $\mathrm{CN}$ members.

1) Workshops and seminars: Several workshop and seminar events are organized by existing CNs (AWMN, Sarantaporo.gr, guifi.net). Experienced members share their knowledge with new members, exchange ideas and present available technical solutions. Guifi.net is quite active in organizing workshops and training seminars i.e., guifi labs ${ }^{14}{ }^{15}$, the $\mathrm{SAX}^{16}$, or

\footnotetext{
${ }^{14} \mathrm{http}: / /$ www.guifiraval.net/

${ }^{15} \mathrm{https} / / /$ guifi.net/en/event

${ }^{16} \mathrm{https}: / / \mathrm{sax} 2016$.guifi.net
}

supports related events FOSDEM ${ }^{17}$, the Dynamic Coalition on Community Connectivity (DC3 $)^{18}$.

AWMN workshops aim at enhancing members' technical skills by disseminating knowledge and technical expertise, interacting with people that have the same interests, strengthening the bonds within the community and new member training. In a different approach, Sarantaporo.gr workshops are more focused to the broader community of locals (with or without technical expertise), inform people about the operation of the network and share knowledge over the wireless networking principles and the development of community networks.

2) Online material for DIY fans: CNs invest effort to derive manuals and how-to documents so that users can learn more about technical matters and be able to set up their own nodes. Freifunk, Ninux, AWMN, guifi.net follow this practice and develop guides that provide technical instructions on actions and requirements of setting up nodes, FAQs and other useful information. Participants are encouraged to self-educate and "take matters into their own hands" instead of relying to "experts" and behaving as consumers of service. In cases, where online material is not enough they can always get advice in $\mathrm{CN}$ forums, or retrieve contact info of node owners.

\section{Local applications and services as incentives}

The applications running over the network can themselves be considered as mechanisms motivating persons to join the network ${ }^{19}$. Such services range from network connectivity to communication, entertainment and privacy. Social tools such as clouds, chats, forums, data exchange and entertainment are present in a variety of CNs and they usually gather the interest of the most active users within the $\mathrm{CN}$.

$\mathrm{CN}$ services and applications that store data or process locally can serve as privacy-related incentive mechanisms for $\mathrm{CN}$ participants avoiding the exposure to not well understood and often privacy-unfriendly practices of commercial data storage solutions. More often than not, such services involve the deployment of distributed cloud solutions that are deployed locally across the $\mathrm{CN}$ nodes, that process and store users' data without dependence on external cloud services or need to interact with the public Internet.

The implementation of Cloudy in the Guifi.net is a characteristic example of community cloud services. Cloudy is an open source community cloud platform designed to host local applications in CNs. The software is run in distributed computing devices owned by $\mathrm{CN}$ participants. It provides services such as infrastructure services, service discovery, network management and user services (PaaS) [67] and it is open to the provision of new ones as Docker containers that can be shared amongst the community.

\footnotetext{
${ }^{17}$ Free and Open Source Software Developers' European Meeting: https: //en.wikipedia.org/wiki/FOSDEM

${ }^{18} \mathrm{https} / / /$ www.intgovforum.org/cms/175-igf-2015/

3014-dynamic-coalition-on-community-connectivity-dc3

${ }^{19}$ There are arguments both in favour of the importance of local services in CNs [66], but also doubts that local services can make an impact on CNs considering that public Internet covers any application needs on the side of the user [11]
} 


\begin{tabular}{|l|c|c|c|c|}
\hline Mechanisms & Volunteers & Users & Private sector service providers & Public agencies \\
\hline Direct reciprocity & & $\mathrm{x}$ & & \\
\hline Indirect reciprocity & & $\mathrm{x}$ & & \\
\hline Punishment of free-riders & $\mathrm{x}$ & & & \\
\hline Community currencies & & $\mathrm{x}$ & $\mathrm{x}$ & \\
\hline Game-theoretic & & $\mathrm{x}$ & $\mathrm{x}$ & \\
\hline Financial compensation & & & & \\
\hline Local data storage infrastructure & & $\mathrm{x}$ & & \\
\hline Social events and meetings & $\mathrm{x}$ & $\mathrm{x}$ & & \\
\hline New member induction processes & & $\mathrm{x}$ & & \\
\hline Workshops and seminars & & $\mathrm{x}$ & & \\
\hline Online material for DIY fans & & $\mathrm{x}$ & $\mathrm{x}$ & \\
\hline Local applications and services & & $\mathrm{x}$ & $\mathrm{x}$ & \\
\hline Operation as legal entities & & $\mathrm{x}$ & $\mathrm{x}$ & \\
\hline Licenses and Agreements & & $\mathrm{x}$ & $\mathrm{x}$ & \\
\hline
\end{tabular}

TABLE V: Incentive mechanisms and relevance to the $\mathrm{CN}$ stakeholders.

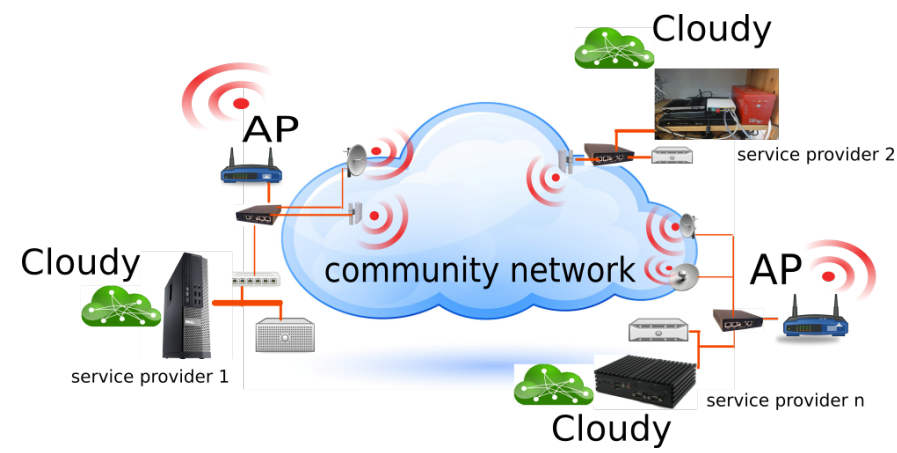

Fig. 8: Community cloud in Guifi.net running the Cloudy distribution on diverse hardware.

Cloud computing infrastructures can be developed in various ways but face severe challenges due to the nature of CNs: hardware and software diversity with various options for inexpensive material, decentralized management, where users contribute and manage their own resources, and rapid changes in the number of contributing nodes.

There are quite a few possible ways to extend the functionalities of Community Clouds. CN resource sharing beyond bandwidth resources can be extended to computing resources [31]. A Community Cloud can be used in conjunction with Grid Computing techniques [68]. Distributed Community Clouds that follow the topology of CNs can be enhanced with techniques to incentivize resource sharing according to nodes' levels of resource contribution [50].

Besides the aforementioned cloud services, CNs can host other types of applications as well. Several CNs have implemented a broad variety of services and applications, while others are at a more initial stage of service and application provision. In CNs like Sarantaporo.gr and i4Free, the main service of interest is Internet access. Yet, Internet access is not always on offer by the $\mathrm{CN}$ : Ninux does not provide any Internet service at all; guifi.net offers the ability only through private Internet service providers operating over the $\mathrm{CN}$; and, in other networks, such as the AWMN, members occasionally share their Internet connections with other users through APs.

Networks built by people with technological background tend to elaborate more on the provision of non-professional services. Tools for communication such as chat, email servers, mailing lists, wikis, forums, data exchange, entertainment like broadcast radios, podcasts and streaming are common services found in most CNs (AWMN, Ninux, Freifunk, guifi.net). AWMN and Ninux users have also access to VoIP and chats, guifi.net users to videoconferencing, AWMN and guifi.net users to local clouds and FFDN, Freifunk and AWMN users to collaborative writing tools. Apart from the basic services used in most $\mathrm{CNs}$, there are also several $\mathrm{CN}$-specific ones, i.e., multi-player gaming, broadcasting, live streaming, elearning, local search engines (Quicksearch, Wahoo, Woogle) in AWMN, web proxies, FTP or shared disk servers, XMPP instant messaging servers, IRC servers, cloud services as the Cloudy distribution [67] in guifi.net, Internet cube, BitTorrent tracker, IndeCP or Internet service in FFDN, private VoIP service and weather monitoring in Sarantaporo.gr.

Besides the applications that are currently in use in different $\mathrm{CNs}$, several others have been proposed in literature or are currently under development.

Crowdsourcing applications are one such example. They have the potential to match very well the participatory nature of wireless community networks, i.e., participatory networking [25] and the strong community-oriented social structure met in most developing regions. In the crowdsourcing paradigm, individual users solicit information, content or service from groups of people. The community dimension only strengthens the case for such applications since the community bonds serve as additional socio-psychological incentives for the active participation and contributions of end users. The resources that $\mathrm{CN}$ members share can serve as the media, where users (mobile or not) connect to post tasks or get informed about available task announcements. Users receive explicit rewards such as monetary payments or virtual credits for services they offer [69].

Another example is VoIP services. Nomadic users (consumers of bandwidth) utilize the community-based Internet access (producers of bandwidth) to get VoIP, as a low cost alternative to traditional cellular telephony [70], [71]. 


\section{E. Lawful framework of operation}

An operational framework of $\mathrm{CNs}$ (legal status, rights, obligations) which is not well defined may impede the attraction of new participants. The level of support of $\mathrm{CN}$ initiatives by the state or local administration has an impact on users' decisions to join or not the network [72]. When local authorities or another third-party organization with clear legal status are involved, e.g., by signing licenses, the user's concerns are easier overcome and the decision to participate looks far less risky. The response of most $\mathrm{CN}$ initiatives to these reservations is to develop legal entities, and set forth licenses and agreements as legal documents specifying the terms and conditions of participation in the network.

1) Operation as legal entities: The majority of CNs have developed legal entities to represent the network to third parties (Table III-B3). For example, Guifi.net created the guifi.net Foundation, AWMN the Association of AWMN, FFDN consists of non-profit member organizations registered as telecom operators, Sarantaporo.gr operates as a non-profit civil partnership subject to the Greek legal framework about NPOs, Freifunk has the Forderverein freie Netzwerke e.V. as a reference NPO authority, TakNet is a social enterprise and B4RN a community benefit society.

2) Licenses and Agreements: Besides the legal status, CNs normally make use of legal documents, such as Licenses and Agreements, to specify the frame of their members' participation and their own interaction with third-party entities.

Guifi.net and FFDN utilize a Network Commons License (NCL) for establishing the rights and duties of subscribed participants. Moreover, guifi.net has developed collaboration agreements (Type A, Type B, Type $C$ ) that define the terms of conditions of third party collaboration within the network. Any private sector entity that wants to perform economic activities and use a significant amount of resources of the network has to sign an Agreement with the Foundation and participate in the compensation system (section V-A4). Freifunk uses the PicoPeering Agreement that promotes the free exchange of data within the network Ninux participants comply with the Ninux manifesto, which is a variation of the PicoPeering Agreement.

\section{F. Incentive mechanism classification}

Several of the incentive mechanisms that are described in sections from V-A to V-E have never gone beyond the paper analysis stage. On the other hand, several others are indeed applied in existing CNs. The financial compensation system of guifi.net, the social events, meetings and workshops organized by many CNs, the adoption of licences in Freifunk and guifi.net, as well as the introduction of a lawful operational framework serve, one way or another, as incentive mechanisms that motivate the participation of different types of stakeholders in $\mathrm{CN}$ initiatives, as shown in Table V-C2.

Some of these incentive mechanisms apply almost invariably to all CNs. The lawful operational status, for example, is mandatory if the $\mathrm{CN}$ wants to attract critical masses of users, but also private sector entities and the support from public agencies. Equally common among $\mathrm{CNs}$ is the care for social events and meetings that can strengthen the links between their members and satisfy socio-cultural motives of users. On the contrary, incentive mechanisms of economical nature, such as the financial compensation scheme and the donation certificates issued bu guifi.net for tax deduction purposes are more relevant in CNs that support commercial operations over them.

For sure, it would be rather wise to match the incentive mechanisms with the different stakeholder types. Hence, volunteers would be more responsive to incentive mechanisms that underline political and cultural causes; private sector service providers would respond, maybe exclusively, to incentive mechanisms with economic implications; and local authorities will be much more prone to get involved when they realize that public expenses can be saved or some political strategic objective be served through this involvement.

By far, the majority of incentive mechanisms target $\mathrm{CN}$ users. One aspect that is not well understood is how the effectiveness of a mechanism varies with different features of the community; namely, if we could have a characterization of a community according to a fixed set of attributes (urban vs. rural, educational level, professional background, dominant political preferences) that could predict which incentive mechanism would best mobilize its members. An important parameter in this context is the size of the community. Characterizations along attributes is easier if the community is small $^{20}$ and with roughly uniform interests and professional background. As their size grows, such characterizations become harder and so does any attempt to predict the suitability of incentive mechanisms.

\section{LESSONS LEARNED}

In what follows we codify main lessons learned through the almost two-decade long experience with CNs:

- The economic sustainability of a $\mathrm{CN}$ requires self-funding procedures, through which the $\mathrm{CN}$ will be able to cover the necessary expenses. Funding can arise also from private donations, collaborations with commercial service providers, or public subsidies. Nevertheless, the experience suggests that the $\mathrm{CN}$ should be able to secure its main funding through subscriptions and local resources of its own members. In one case, e.g., the B4RN network [4], the $\mathrm{CN}$ issues shares that are purchased by community members. Both in the case of B4RN and guifi.net, the investments/donations to the $\mathrm{CN}$ are awarded with tax deductions. In any case, the economic models need to take into account the specificities of each $\mathrm{CN}$ since not all models can be exported from one to another [73].

- The way that a $\mathrm{CN}$ is approached by the surrounding environment also depends on the way that the $\mathrm{CN}$ approaches the pool of people it refers to. The impact of a $\mathrm{CN}$ is greatly dependent on the way that the people in the area embrace it. It is usually measured in terms of satisfying basic needs such as provision of appealing services or

\footnotetext{
${ }^{20} \mathrm{But}$ not too small. The $\mathrm{CN}$ will not be sustainable if there are not enough human resources to pull from.
} 
applications. This demands a deep understanding of the daily life and problems of the local population and measures for inclusiveness of a variety of people.

- Ambiguity in terms of CN organization and lawful operation may hurt the sustainable interest in the $\mathrm{CN}$. The $\mathrm{CN}$ operations should be clearly stated internally to its own community and area of operation and externally to third parties, organizations, other companies, governments. The establishment of a legal entity for the $\mathrm{CN}$ and the use of licenses detailing the terms and conditions of participation in the $\mathrm{CN}$ are key to its viability.

- Competition and legal disputes with telecom companies can jeopardize the entire $\mathrm{CN}$ project. Instead, the $\mathrm{CN}$ should invest effort to establish, and favor through its operational models, synergies with other stakeholders, including private sector companies.

- Access to the network has to be regulated in order to avoid depletion of network resources and unfairness in participation. Free riding and selfish behaviors can be dealt by using blockchains and community currencies, reciprocity-based mechanisms, but also penalty-driven mechanisms.

- The human factor is important. Human interaction should be promoted either through socializing process leveraging both online tools and face-to-face meetings. Education and training practices as well as locally focused applications such as community cloud computing and services are also important. Together, they promote cooperation amongst participants, create a local sense of ownership, and develop digital sovereignty through experimentation and exchange of knowledge.

In summary, sustainability cannot be reached following a set of exhaustive rules and there are no clearcut answers for approaching it. However, checkpoints or indicative guidelines can be used to assess it. An attempt to summarize those is the evaluation form presented in the appendix, which is the outcome of fieldwork in the context of [11].

\section{OPEN CHALLENGES AT THE TECHNOLOGICAL AND REGULATORY FRONT}

The practices of $\mathrm{CNs}$ and their creativity in addressing the multifaceted motives of their stakeholders, as exposed in sections III-V, are key to their sustainability. Yet, there are further challenges at the technological and the policymaking/regulatory front that will also prove decisive in their sustainability question. In the remainder of this section, we review these challenges and for each one we describe current practices or possible directions for coping with them.

\section{A. Technology}

1) Community networks and LTE Unlicensed: The strong growth of mobile data traffic over the last years has increased the demand for additional capacity and spectrum resources for mobile cellular networks. One of the solutions promoted by the telecom industry is to expand the LTE standard to also operate in unlicensed spectrum. The band considered in this context is the $5 \mathrm{GHz}$ UNII (Unlicensed National Information Infrastructure) band, which is used by Wi-Fi networks (IEEE $802.11 \mathrm{a} / \mathrm{n} / \mathrm{ac} / \mathrm{ax}$ ) but also other wireless systems such as weather radars and medical devices [74]. This potential coexistence of LTE with $\mathrm{WiFi}$ has raised concerns to many operators of WiFi networks, including $\mathrm{CNs}$, who are afraid that LTE might completely crowd WiFi out of the band by utilizing all the available bandwidth [75]. The studies that have been carried out on the impact of this co-existence report contradicting outcomes. Those from telecom industry (e.g., [76]) have been rather comforting hinting at a low impact of this co-existence on the performance of WiFi networks. Other studies [77], [78] reported a fully asymmetrical impact on the two systems, WiFi networks being the ones that suffer serious performance degradation.

In either case, the battle for $\mathrm{CNs}$, and more broadly $\mathrm{WiFi}$ network operators, relates to rendering LTE radio technology friendlier against WiFi. This implies adding mechanisms to the standard that enable it to share the spectrum resources of the unlicensed band with $\mathrm{WiFi}$ and other systems. The friendliness of these mechanisms, which are sketched in Fig. 9 and briefly presented in the remainder of this subsection, varies considerably.

Dynamic Channel Selection: This refers to the basic flexibility that can be embedded into LTE implementations so that LTE devices choose idle channels for their transmissions in the unlicensed band, when such are available. This is a must-have capability for LTE but does not address the cases of conflict with WiFi systems.

Duty cycling: This mechanism is considered in countries such as China, South Korea but also United States, where the telecom regulations pose an upper limit to the time that transmission bursts from any given system can occupy the spectrum in an unlicensed band. The mechanisms demands that LTE cells periodically interrupt their own transmissions to let devices of other systems such as WiFi, take their turn in making transmissions. The mechanism is incorporated in the 3GPP LTE Release 10 system as the Almost Blank Subframe (ABS) capability in the context of LTE HetNets, the term used by $3 \mathrm{GPP}$ to denote networks that consist of cells of various sizes, including femto-, pico, micro-, and macrocells. There, the ABS mechanism aims to manage the interference betweem different types of cells, by restricting data transmissions from the macro cell in certain time (sub)frames, which can then be used by smaller cells in parallel. The mechanism envisages some flexibility with respect to the duration of these cycles, in that the LTE blank subframes can be shorter or longer depending on utilization of the band by the LTE and other systems.

Listen-Before-Talk: With Listen-Before-Talk (LBT), devices aiming to transmit first sense the medium and continue to transmit as long as they do not detect another transmission for some time interval, mainly in the form of electromagnetic energy that exceeds considerably the level of white noise. If they do, they back off and only reattempt a transmission, sensing the medium anew, after some time interval (back-off time). The mechanism reduces the probability of collisions between transmission of the same or different systems using 
the unlicensed band. Implementation of the LBT mechanism is mandatory for LTE in Europe and Japan, where the legislation demands this medium sensing before any transmission in the unlicensed bands. Current proposals for the LBT implementation in 3GPP differentiate with respect to (a) whether the backoff is random or not; (b) as far as it is random, whether its value is drawn from a window of possible values (contention window) that is fixed or variable. For comparison, the carrier sense mechanism standardized for years in WiFi networks implements random backoff with a variable contention windows that increases with the anticipated congestion in the medium. Clearly, such as solution is the friendliest implementation of the LBT mechanism and the preferred one by WiFI network operators, including the $\mathrm{CN}$ operators.
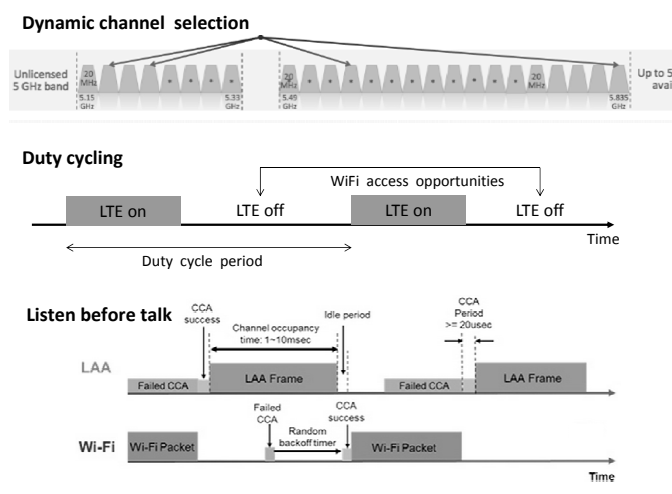

Fig. 9: Candidate solutions for co-existence of WiFi and LTE in unlicensed bands.

2) Community networks and 5G: The LTE technology will be the cornerstone for the next generation of mobile cellular systems, commonly advertised as 5G. Highly ambitious performance indicators have been been set for these systems [79] including: 1000-fold increase of the aggregated network capacity; 10-fold decrease of the latency, when compared to 4G; access speeds exceeding $100 \mathrm{Mbps}$ for $95 \%$ of the users; up to 10.000 connected devices per Base Station (BS).

Such objectives call for extreme densification and diversification of the radio network access points, all the way from macro- down to femto-cells. They also assume breakthroughs in the physical layer technologies that will help overcome the adverse radio propagation conditions in the $\mathrm{mm}$ wavelength range $(30-300 \mathrm{GHz})$ and render them usable for mobile wireless communications [79]. Finally, they demand cost-effective technologies in the backhaul network to support the high data rates promised in the radio access network. The only technology currently available for the backhaul network is optic fiber. Yet, the fiber-to-the-home (FTTH) deployment requires considerable investments, which are currently ongoing in urban areas but are unlikely to experience in suburban and rural areas [80]. So far, no plan has been articulated for the $5 \mathrm{G}$ profitability in rural and suburban areas with low average revenues per user (ARPU). Hence, the plausible concern is that $5 \mathrm{G}$ will end up enlarging the gap between those connected and those unconnected, rather than bridging it, by improving further the connectivity of those who already have it and raising the cost barrier higher for the rest [81] [82].

Community networks could play a significant role in disproving such concerns. They often have become bearers of innovative cost-effective communications solutions, essentially leveraging the high availability of WiFi-enabled phones even in areas of low ARPU. In the Serval project [83], they use low-end battery-powered devices to realize a backhaul mesh network at UHF frequencies that presents 802.11 access points to end users. Likewise, in the LibreRouter project, launched by the Altermundi NGO in Argentina, they produce fully open multi-radio 802.11 access points, with support for Wi-Fi and other wireless access technologies [84]. Their aim is to ease the deployment of wireless mesh networks by communities without demanding almost any technical skill.

Nowadays, with the use of directional antennas, proprietary extensions to the MAC layer implemented by many vendors, and multiple gateways, $\mathrm{CNs}$ have managed to scale up and provide exceptional access rates to their users at significantly lower cost than cable-driven solutions. They have even shown their potential to scale up the overall capacity by deploying their own optic fiber cables. Although the fiber deployment costs per mile, including roadwork, licenses etc, amounts lies in the order of 60,000USD [4], communities in rural areas have managed to suppress this cost considerably by laying fiber in private land and mobilizing the community in the fiber deployment work.

3) Security: The security challenges for $\mathrm{CNs}$ are not intrinsically different from what other networks face. The greatest advantage of CNs, when compared to other network infrastructures, technologies or service models, refers to data privacy. The operation of the network, including security policies and incidents, is handled by a mix of professionals and volunteers. This is both a strength since users are on average better trained and committed, and a weakness as diversity means less uniform control. Open participation in the governance of the network infrastructure demands that participants, including end-users, are more aware and can decide on data privacy policies and practices. The result is that typically data is kept, saved and processed at a local level without being exposed to public and commercial storage and processing units in the Internet. In wireless $\mathrm{CNs}$, users do not need to authenticate and utilize sensitive credentials for connecting to the network. In some networks, like Freifunk or guifi.net, participants offer anonymous Internet access proxies and the $\mathrm{CN}$ organization provides technical and legal support to preserve the service. Although this feature is of great importance for preserving user anonymity, it can sometimes make the network susceptible to misuse and free riding behaviors. 


\section{B. Policy making and regulation}

There are recommendation from international organizations such as ITU, Internet Society or United Nations to define regulatory frameworks that facilitate the universalization of Internet access for development and participation in society. The D-REC-D.19 [85] by ITU (2010) recommends to include provision of telecommunications/ICTs in rural and remote areas in their national development plans, and highlights the importance of community access to ICT facilities and services. The Internet Society (ISOC) is one among several other civil society organizations that insists on the need for universal, open and sustainable Internet access [86]. The United Nations has declared in numerous events that sustainable development goals cannot be achieved without affordable and universal access to ICTs and broadband connectivity, and has defined Goal 9.c. as "significantly increase access to ICT and strive to provide universal and affordable access to the Internet in least developed countries by 2020 ".

However, at the policy-making level, CNs need to cope with:

1) Lack of national legislation: Up to now, most countries lack a clear regulatory framework addressing the existence of CNs. Hence, they often tend to operate in a gray zone, which evidently poses limits their development potential and their visibility.

Having said this, and in the context of recommendation ITU D-REC-D.19 and others, there are cases of countries that have put forward a favorable legal framework for CNs. These include initiatives for sharing licensed spectrum/dynamic spectrum Access in the TV White Spaces (TVWS) in regions of Asia, Africa and America; innovative licensing schemes such as TVWS or $5 \mathrm{GHz}$ spectrum backed by social or welfare purpose in India; the GSM spectrum (824-849 and 869-894 $\mathrm{MHz}$ ) specifically for social purpose use in Mexico; and the new regulation on radio equipment that eliminates licensing requirements for providers serving fewer than 5,000 users in Brazil [87].

2) Lack of representation in policy-making bodies: At the moment, CNs lack an institution that could give them representation and strengthen their voice in global policy-making organizations. Instances of federation exist at national level: guifi.net, in Spain, the French association FFDN, in France, Ninux, in Italy are all $\mathrm{CN}$ associations in Europe bringing together several CNs that operate locally in villages/towns/cities. This form of organization emerged primarily as a means to more efficiently address organizational aspects and share costs of Internet connections.

However, there is no concrete federal representation at continental or global level, which would provide CNs with credible representation in meetings with stakeholders such as governments and global organizations, and let them intervene to global policies more effectively. The need for such representation was best evidenced, at least in Europe, in the case of the Radio Equipment Directive 2014/53/EU ${ }^{21}$. The directive, which was issued in 2014 with the purpose of harmonizing the relevant legislation across EU member states, prohibits

\footnotetext{
${ }^{21} \mathrm{http}: / /$ eur-lex.europa.eu/legal-content/EN/TXT/HTML/?uri=CELEX $\% 3 \mathrm{~A} 32014 \mathrm{~L} 0053$
}

changes in the software/firmware running on wireless devices by third parties. This has been a severe blow for European CNs since many of them could grow exactly by altering the software/firmware of commercial off-the-shelf wireless network equipment.

There are currently attempts to fill this gap. A step towards this direction was the Open Letter ${ }^{22}$ addressed to EU policymakers with respect to the ongoing revision of Telecoms Code. This letter was co-authored and signed by a number of $\mathrm{CNs}$ and supporting organizations worldwide. Similar efforts are currently ongoing within the Internet Society to establish a Special Interest Group on CNs. Its mission will be to serve as an umbrella organization that will promote the $\mathrm{CN}$ requirements and organize interventions in policy-making and regulation bodies about them. It will also assist in establishing new legal frameworks that will recognize CNs as alternative telecommunication networks, acknowledge their impact and specificities and safeguard their rights and existence when needed.

\section{CONCLUSIONS}

Our survey has addressed the issue of sustainability in community networks, accounting for the various political, socio-cultural and economic perspectives of their participants and stakeholders. We explained how CNs instantiate open and shared network infrastructure models, when compared to the dominant trend of vertical business models in the telecoms sector. Possible funding sources were analyzed, including their members' subscriptions and funds from private and public entities. Economic sustainability is a challenging issue, which seems to be a necessary but not sufficient condition for the sustainable operation of the CN. Satisfying socio-cultural and politic aspirations is also key to this end.

The activities of each $\mathrm{CN}$ involve a specific mix of four types of stakeholder entities (i.e., volunteers, users, private sector entities, public agencies). Representative CNs have been discussed with respect to incentive mechanisms they put in place to motivate the engagement of these stakeholders. We have highlighted best practices and lessons learned in this respect, together with challenges of technical and regulatory nature for the long-term sustainability of the $\mathrm{CN}$ paradigm.

\section{ACKNOWLEDGMENTS}

The authors acknowledge the support of the European Commission through the Horizon 2020 project netCommons (Contract number 688768, duration 2016-2018).

\section{APPENDIX A \\ SUSTAINABILITY CHECKPOINTS}

\section{1) Economy: Market and model of provision}

- To which extent is the community network supported by non-profit/community based network access and services provision?

- To which extent does the community network rely on a commercial provider? What is the nature of this provider

\footnotetext{
${ }^{22} \mathrm{https} / / /$ lqdn.co-ment.com/text/R142W44XAc6/view/
} 
(e.g. for-profit vs. social enterprise, or local vs. nonlocal)?

- To which extent does the model of network provision of the community network face competition from commercial for-profit telcos on the basis of quality of signal/provision, lower cost and/or better network maintenance?

\section{Resources:}

- To which extent does the community network manage to survive economically, i.e. to afford the necessary hardware and labour-power necessary for running the network?

- To which extent can the community network ensure that it has enough resources, supporters, workers, volunteers, and users?

- To which extent does the community network rely on internal funding sources?

- To which extent does the community network rely on external funding sources? How regular are they?

- Are there possibilities for the community network to obtain public or municipal funding or to co-operate with municipalities, public institutions or the state in providing access and services?

- To which extent does the community network rely on a single individual or a small group of actors for providing the necessary resources (time, skills, money)?

Network wealth for all:

- To which extent does the community network provide gratis/cheap/affordable network and Internet access for all?

- If subscriptions are used, are they affordable?

- To which extent are there different pricing schemes such as for residential users, small enterprises, bigger firms, and public institutions (e.g. schools)?

- How can the community avoid or lower the digital divide?

- What technological skills are required of the average user to benefit from the community network?

Needs:

- To which extent are the community needs served by the community network?

- To which extent are the needs of diverse individuals (e.g. by gender, age, nationality) and groups in the community served by the community network?

- To which extent are the needs of local businesses served by the community network?

\section{2) Politics: Participation/governance}

- How is the community network governed? How does it decide on which rules, standards, licences, etc. are adopted?

- To what extent does the community network allow and encourage the participation of community members in governance processes?

- To what extent are there in place mechanisms for conflict resolution and for proceedings in the case of the violation of community rules?

Data ownership and control
- To which extent does the community network enhance the protection of privacy of user data?

- To which extent does the community network provide opportunities for active user involvement in the management of their data? What are the skills required and how are they provided?

- To which extent and for how long are user data kept in servers controlled centrally (e.g. by the network administrators)? How do you guarantee that data storage is done in line with data protection regulation and is privacyfriendly?

3) Culture: Community spirit:

- How closely knit is the community? To which extent are trust and solidarity present and how are they manifested?

- To which degree is the community network a geek public that has an elitist, exclusionary culture or a community public that is based on a culture of unity in diversity?

- To which extent does the community network provide mechanisms for learning, education, training, communication, conversations, community engagement, strong democracy, participation, co-operation, and well-being? In what ways?

- To which degree is the community network able to foster a culture of togetherness and conviviality that brings together people? In what ways?

\section{REFERENCES}

[1] European Commission, "Guide to high-speed broadband investment," Tech. Rep. Release 1.1, October 2014

[2] R. Baig, R. Roca, F. Freitag, and L. Navarro, "Guifi.net, a crowdsourced network infrastructure held in common," Computer Networks, vol. 90, no. C, pp. 150-165, 2015.

[3] W. Waites and et al, "Remix: A distributed internet exchange for remote and rural networks," in Proceedings of the 2016 Workshop on Global Access to the Internet for All, GAIA '16, pp. 25-30, 2016.

[4] "Broadband for the Rural North Ltd.." https://b4rn.org.uk/. Last accessed: 2017-12-22.

[5] B. C. for Sustainable Development, "State of broadband report 2016," State of Broadband report, no. 1, pp. 1-2, 2016.

[6] International Telecommunication Union, "Trends in telecommunication reform 2008: Six degrees of sharing," Tech. Rep. D-PREF-TTR.10, July 2009.

[7] O. for Economic Co-operation and Development, "Broadband networks and open access," OECD Digital Economy Papers, no. 218, pp. 1-46, 2013.

[8] C. Szabó, K. Farkas, and Z. Horváth, "Motivations, design and business models of wireless community networks," Mobile Networks and Applications, vol. 13, no. 1-2, pp. 147-159, 2008.

[9] E. Lawrence, M. Bina, G. Culjak, and T. El-Kiki, "Wireless community networks: Public assets for 21st century society," in Fourth International Conference on Information Technology (ITNG), 2007.

[10] P. A. Frangoudis, G. C. Polyzos, and V. P. Kemerlis, "Wireless community networks: an alternative approach for nomadic broadband network access," IEEE Communications Magazine, vol. 49, pp. 206-213, May 2011.

[11] C. Fuchs, M. Michalis, and D. Boucas, "The Multiple Aspects of Politics of Sustainability in Community Networks: Definitions, Challenges, and Countermeasures (v2)," tech. rep., netCommons Deliverable D2.2, Jan. 2017.

[12] C. Fuchs, M. Michalis, and D. Boucas, "The Multiple Aspects of Politics of Sustainability in Community Networks: Definitions, Challenges, and Countermeasures (v1)," tech. rep., netCommons Deliverable D2.1, Jun. 2016.

[13] L. Navarro, R. Baig, F. Freitag, E. Dimogerontakis, F. Treguer, M. Dulong de Rosnay, L. Maccari, P. Micholia, and P. Antoniadis, "Report on the Existing CNs and their Organization (v2)," tech. rep., netCommons Deliverable D1.2, Sept. 2016. 
[14] M. Forzati, C. P. Larsen, and C. Mattsson, "Open access networks, the swedish experience," in 12th International Conference on Transparent Optical Networks (ICTON), pp. 1-4, 2010.

[15] E. Ostrom, Governing the commons: the evolution of institutions for collective action. Cambridge University Press, Nov. 1990.

[16] G. Moore, "The fair trade movement: Parameters, issues and future research," Journal of business ethics, vol. 53, no. 1, pp. 73-86, 2004

[17] R. Baig, L. Dalmau, R. Roca, L. Navarro, F. Freitag, and A. Sathiaseelan, "Making community networks economically sustainable, the guifi.net experience," in Proceedings of the 2016 Workshop on Global Access to the Internet for All (GAIA), pp. 31-36, ACM, 2016

[18] J. Barcelo, B. Bellalta, R. Baig, R. Roca, A. Domingo, L. Sanabria, C. Cano, and M. Oliver, "Bottom-up broadband initiatives in the commons for europe project," CoRR, 2012.

[19] C. Aichele, R. Flickenger, C. Fonda, J. Forster, I. Howard, T. Krag, M. Zennaro, et al., Wireless networking in the developing world. Limehouse Book Sprint Team, 2006.

[20] J. Camp, J. Robinson, C. Steger, and E. Knightly, "Measurement driven deployment of a two-tier urban mesh access network," in Proceedings of the 4th international conference on Mobile systems, applications and services, pp. 96-109, ACM, 2006.

[21] P. Micholia, M. Karaliopoulos, I. Koutsopoulos, G. Klissiaris, and P. Antoniadis, "Incentives for Participation and Active Collaboration in CNs (v1)," tech. rep., netCommons Deliverable D2.3, Jan. 2017.

[22] M. Pérez, P. Boronat, J. A. Gil, and A. Pont, guifi.net: A Bottom-up Initiative for Building Free Telecommunication Infrastructure, pp. 144155. Springer International Publishing, 2016.

[23] J. Barcelo, "Bottom-up Broadband: Free Software Philosophy Applied to Networking Initiatives," 2014.

[24] M. Oliver, J. Zuidweg, and M. Batikas, "Wireless commons against the digital divide," in IEEE International Symposium on Technology and Society, pp. 457-465, 2010.

[25] D. Vega, R. Meseguer, and F. Freitag, Analysis of the Social Effort in Multiplex Participatory Networks, pp. 67-79. Springer International Publishing, 2014.

[26] L. F. Pedraza, A. Cepeda Ruiz, and D. Ballesteros, "Community wireless network development in ciudad bolívar," Tecnura, vol. 17, no. 36 , pp. 10-20, 2013.

[27] M. Korn, "Hybrid wireless networks for neighborhood communities," in Workshop on Residents' Democratic Engagement in Public Housing and Urban Areas at Aarhus 2015: Critical Alternatives, 2015.

[28] D. L. Johnson, E. M. Belding, K. Almeroth, and G. van Stam, "Internet usage and performance analysis of a rural wireless network in macha, zambia," in Proceedings of the 4th ACM Workshop on Networked Systems for Developing Regions (NSDR), pp. 7:1-7:6, ACM, 2010.

[29] A. Lertsinsrubtavee, L. Wang, A. Sathiaseelan, J. Crowcroft, A. Weshsuwannarugs, N.and Tunpan, and K. Kanchanasut, "Understanding internet usage and network locality in a rural community wireless mesh network," in Proceedings of the Asian Internet Engineering Conference (AINTEC), pp. 17-24, ACM, 2015.

[30] D. W. Mcdonald, "Social issues in self-provisioned metropolitan area networks," in Conference on Human Factors in Computing Systems, ACM, 2002.

[31] A. M. Khan, L. Navarro, L. Sharifi, and L. Veiga, "Clouds of small things: Provisioning infrastructure-as-a-service from within community networks," in 9th International Conference on Wireless and Mobile Computing, Networking and Communications (WiMob), pp. 16-21, 2013.

[32] R. Sofia, A. Bogliolo, F. Sivrikaya, H. Zhu, O. Marce, and D. Valerdi, "User-centric networking and services: part 2 [guest editorial]," IEEE Communications Magazine, vol. 52, no. 12, pp. 16-16, 2014.

[33] M. Bina and G. M. Giaglis, "Unwired collective action: Motivations of wireless community participants," in Proceedings of the International Conference on Mobile Business (ICMB), pp. 31-, IEEE Computer Society, 2006

[34] M. of the guifi.net Foundation, "Municipal ordinance for the deployment of access networks to next-generation telecommunication services in universal format," template for a municipal ordinance, guifi.net Foundation, 2017.

[35] P. Antoniadis, J. Martignoni, and L. Navarro, "Economic Sustainability of CNs (v1) Introducing Community Currencies," tech. rep., netCommons deliverable D2.4, Dec. 2016.

[36] L. Forlano, A. Powell, G. Shaffer, and B. Lennett, "From the digital divide to digital excellence: global best practices for municipal and community wireless networks," lse research online documents on economics, London School of Economics and Political Science, LSE Library, 2011.
[37] A. Powell and L. R. Shade, "Going wi-fi in canada: municipal and community initiatives," Government Information Quarterly, vol. 23 , no. 3-4, pp. 381-403, 2006.

[38] A. Powell, "Wifi publics: producing community and technology," Information, Communication \& Society, vol. 11, no. 8, pp. 1068-1088, 2008.

[39] B. Braem, C. Blondia, C. Barz, H. Rogge, F. Freitag, L. Navarro, J. Bonicioli, S. Papathanasiou, P. Escrich, R. Baig Vinas, et al., "A case for research with and on community networks," ACM SIGCOMM Computer Communication Review, vol. 43, no. 3, pp. 68-73, 2013.

[40] M. H. Manshaei, J. Freudiger, M. Felegyhazi, P. Marbach, and J.-P. Hubaux, "On wireless social community networks," in Proc. 27th IEEE INFOCOM, April 2008.

[41] A. Mazloumian, M. H. Manshaei, M. Félegyházi, and J.-P. Hubaux, "Optimal pricing strategy for wireless social community networks," in Proc. 3rd Int'l Wkshop on Econ. of Netw. Sys., (Seattle, WA, USA), pp. 103-108, 2008.

[42] M. H. Afrasiabi and R. Guerin, "Exploring user-provided connectivity," IEEE/ACM Trans. on Netw., vol. 24, pp. 542-554, Feb 2016.

[43] "Fon, the world's leading carrier wifi provider."

[44] Q. Ma, L. Gao, Y. F. Liu, and J. Huang, "A game-theoretic analysis of user behaviors in crowdsourced wireless community networks," in Proc. 13th WiOpt, pp. 355-362, May 2015.

[45] G. Gheorghe, R. Lo Cigno, and A. Montresor, "Security and privacy issues in P2P streaming systems: A survey," Peer-to-Peer Networking and Applications, vol. 4, no. 2, pp. 75-91, 2011.

[46] G. Ciccarelli and R. Lo Cigno, "Collusion in Peer-to-Peer Systems," Computer Networks, vol. 55, no. 15, pp. 3517-3532, 2011.

[47] M. A. Nowak, "Five rules for the evolution of cooperation," Science, vol. 314, no. 5805, pp. 1560-1563, 2006.

[48] E. C. Efstathiou, P. A. Frangoudis, and G. C. Polyzos, "Stimulating participation in wireless community networks," in Proceedings of the 25th IEEE International Conference on Computer Communications (INFOCOM), pp. 1-13, 2006.

[49] E. C. Efstathiou, F. A. Elianos, P. A. Frangoudis, V. P. Kemerlis, D. C. Paraskevaidis, G. C. Polyzos, and E. C. Stefanis, "Practical incentive techniques for wireless community networks," in 4th International Conference on Mobile Systems, Applications, and Services (MobiSys) Demo Session, Citeseer, 2006.

[50] U. C. Buyuksahin, A. M. Khan, and F. Freitag, "Support service for reciprocal computational resource sharing in wireless community networks," in IEEE 14th International Symposium on "A World of Wireless, Mobile and Multimedia Networks" (WoWMoM), pp. 1-6, 2013.

[51] U. C. Büyükşahin, On Incentive Mechanisms for Resource Sharing in Community Clouds. PhD thesis, Universitat Politécnica de Catalunya, 2013.

[52] D. Vega, R. Messeguer, S. F. Ochoa, J. A. Pino, F. Freitag, E. Medina, and D. Royo, "Sharing hardware resources in heterogeneous computersupported collaboration scenarios," Integrated Computer-Aided Engineering, vol. 20, no. 1, pp. 59-77, 2013.

[53] S. Buchegger, J. Mundinger, and J. Y. L. Boudec, "Reputation systems for self-organized networks," IEEE Technology and Society Magazine, vol. 27, no. 1, pp. 41-47, 2008.

[54] A. Satsiou and L. Tassiulas, "A trust-based exchange framework for multiple services in $\mathrm{p} 2 \mathrm{p}$ systems," in 7th IEEE International Conference on Peer-to-Peer Computing (P2P), pp. 45-52, 2007.

[55] P. Michiardi and R. Molva, "Core: A collaborative reputation mechanism to enforce node cooperation in mobile ad hoc networks," in Proceedings of the IFIP TC6/TC11 Sixth Joint Working Conference on Communications and Multimedia Security: Advanced Communications and Multimedia Security, pp. 107-121, Kluwer, B.V., 2002.

[56] K. Panchanathan and R. Boyd, "Indirect reciprocity can stabilize cooperation without the second-order free rider problem," Nature, vol. 432, no. 7016, pp. 499-502, 2004.

[57] F. Martignon, S. Paris, and A. Capone, "A framework for detecting selfish misbehavior in wireless mesh community networks," in Proceedings of the 5th ACM Symposium on QoS and Security for Wireless and Mobile Networks (Q2SWinet), pp. 65-72, 2009.

[58] E. López and L. Navarro, "Kdet: Coordinated detection of forwarding faults in wireless community networks," in Trustcom/BigDataSE/ISPA, 2015 IEEE, vol. 1, pp. 734-741, IEEE, 2015.

[59] R. Mahajan, M. Rodrig, D. Wetherall, and J. Zahorjan, "Sustaining cooperation in multi-hop wireless networks," in Proceedings of the 2nd Conference on Symposium on Networked Systems Design \& Implementation (NSDI), pp. 231-244, USENIX Association, 2005. 
[60] G. Biczók, L. Toka, A. Gulyás, T. A. Trinh, and A. Vidács, "Incentivizing the global wireless village," Computer Networks, vol. 55, no. 2 , pp. 439-456, 2011.

[61] M. Feldman, K. Lai, I. Stoica, and J. Chuang, "Robust incentive techniques for peer-to-peer networks," in Proceedings of the 5th ACM Conference on Electronic Commerce (EC), pp. 102-111, ACM, 2004.

[62] M. Felegyhazi, J. P. Hubaux, and L. Buttyan, "Nash equilibria of packet forwarding strategies in wireless ad hoc networks," IEEE Transactions on Mobile Computing, vol. 5, no. 5, pp. 463-476, 2006

[63] S. Zhong, J. Chen, and Y. R. Yang, "Sprite: A simple, cheat-proof, credit-based system for mobile ad-hoc networks," in 22nd Annual Joint Conference of the IEEE Computer and Communications (INFOCOM), vol. 3, pp. 1987-1997, IEEE, 2003

[64] S. Zhong, L. E. Li, Y. G. Liu, and Y. Yang, "On designing incentivecompatible routing and forwarding protocols in wireless ad-hoc networks," Wireless Networks, vol. 13, no. 6, pp. 799-816, 2007.

[65] W. Wu, J. C. S. Lui, and R. T. B. Ma, "A game theoretic analysis on incentive mechanisms for wireless ad hoc vod systems," in 10th International Symposium on Modeling and Optimization in Mobile, Ad Hoc and Wireless Networks (WiOpt), pp. 177-184, 2012.

[66] P. Antoniadis, "Local networks for local interactions: Four reasons why and a way forward," First Monday, vol. 21, no. 12, 2016.

[67] M. Selimi, A. M. Khan, E. Dimogerontakis, F. Freitag, and R. P. Centelles, "Cloud services in the guifi.net community network," Computer Networks, vol. 93, no. P2, pp. 373-388, 2015.

[68] A. Marinos and G. Briscoe, "Community cloud computing," in Proceedings of the 1st International Conference on Cloud Computing (CloudCom), (Berlin, Heidelberg), pp. 472-484, Springer-Verlag, 2009.

[69] T. Luo and C. K. Tham, "Fairness and social welfare in incentivizing participatory sensing," in 9th Annual IEEE Communications Society Conference on Sensor, Mesh and Ad Hoc Communications and Networks (SECON), pp. 425-433, 2012.

[70] P. Frangoudis and G. C. Polyzos, "On the performance of secure usercentric voip communication," Computer Networks, vol. 70, pp. $330-$ 344, 2014.

[71] P. Frangoudis and G. Polyzos, "Security and performance challenges for user-centric wireless networking," IEEE Communications Magazine, vol. 52, no. 12 , pp. $48-55,2014$

[72] A. Abdelaal, Social and economic effects of community wireless networks and infrastructures. IGI Global, 2013.

[73] S. Crabu, L. Navarro, M. Dulong de Rosnay, D. Franquesa, and F. Treguer, "Report on the Governance Instruments and their Application to CNs (v1)," tech. rep., netCommons Deliverable D1.3, June. 2017.

[74] M. Labib, J. H. Reed, A. F. Martone, and A. I. Zaghloul, "Coexistence between radar and LTE-U systems: Survey on the $5 \mathrm{GHz}$ band," in Radio Science Meeting (USNC-URSI NRSM), 2016 United States National Committee of URSI National, pp. 1-2, IEEE, 2016.

[75] Q. Chen, G. Yu, and Z. Ding, "Optimizing unlicensed spectrum sharing for LTE-U and WiFi network coexistence," IEEE J.Sel. A. Commun., vol. 34, pp. 2562-2574, Oct. 2016.

[76] HUAWEI, "U-LTE: unlicensed spectrum utilization of LTE," 2014.

[77] Y. Jian, C.-F. Shih, B. Krishnaswamy, and R. Sivakumar, "Coexistence of Wi-Fi and LAA- LTE: experimental evaluation, analysis and insights," in Proc. ICC Workshop on LTE in Unlicensed Bands: Potentials and Challenges, pp. 2325-2331, 2015.

[78] S. Sagari, I. Seskar, and D. Raychaudhuri, "Modeling the coexistence of LTE and WiFi heterogeneous networks in dense deployment scenarios," in Proc. ICC Workshop on LTE in Unlicensed Bands: Potentials and Challenges, pp. 2301-2306, 2015.

[79] J. G. Andrews, S. Buzzi, W. Choi, S. V. Hanly, A. Lozano, A. C. K. Soong, and J. C. Zhang, "What Will 5G Be?," IEEE Journal on Selected Areas in Communications, vol. 32, pp. 1065-1082, June 2014.

[80] M. Jaber, M. A. Imran, R. Tafazolli, and A. Tukmanov, "5G Backhaul Challenges and Emerging Research Directions: A Survey," IEEE Access, vol. 4, pp. 1743-1766, April 2016.

[81] O. Onireti, J. Qadir, M. A. Imran, and A. Sathiaseelan, "Will 5G See its Blind Side? Evolving 5G for Universal Internet Access," in Proceedings of the 2016 workshop on Global Access to the Internet for All, pp. 1-6, ACM, August 2016

[82] M. Eriksson and J. van de Beek, "Is anyone out there? 5G, rural coverage and the next 1 billion," IEEE ComSoc Technology News (CTN), November 2015 .

[83] P. Gardner-Stephen, "The serval project: Practical wireless ad-hoc mobile telecommunications," tech. rep., 2011.

[84] "The librerouter description." https://www.internetsociety.org/sites/ default/files/blogs-media/18_LibreRouter_Innovative-Technologies.pdf. Last accessed: 2017-12-22.
[85] International Telecommunication Union, "Telecommunication for rural and remote areas," Tech. Rep. Recommendation D.19 (03/10), April 2010.

[86] Internet Society, "Global internet report: Open and sustainable internet," Annual report, Internet Society, 2014.

[87] Internet Society, "Policy brief: Spectrum approaches for community networks," Policy report, Internet Society, 2017.

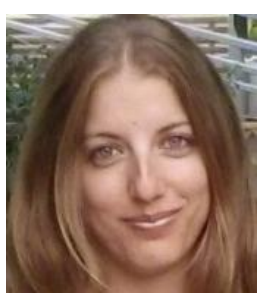

Panagiota Micholia received the Diploma degree in Electrical and Computer Engineering from the Democritus University of Thrace (DUTH), Greece, in 2010 and the M.S degree in Advanced Sciences of Modern Telecommunications from the University of Valencia (UV), Spain, in 2012. She is currently a $\mathrm{PhD}$ candidate at the Department of Informatics, Athens University of Economics and Business (AUEB), Athens, Greece. Her research interests focus on user recruitment and incentives in crowdsourcing systems and community networks.

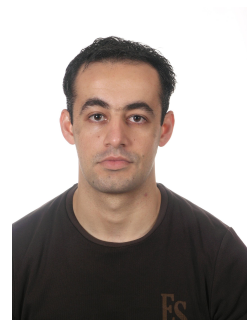

Merkouris Karaliopoulos is a Senior Researcher with the Department of Informatics, in the Athens University of Economics and Business, Greece. He was awarded his Diploma in Electrical and Computer Engineering from Aristotelian University of Thessaloniki, Greece, in 1998, and his $\mathrm{PhD}$ in the same field from the University of Surrey, UK, in 2004. He has had postdoctoral research appointments in the Computer Science Dept. of University of North Carolina at Chapel Hill, NC, USA (2006), the Swiss Federal Institute of Technology, Zurich, Switzerland (2007-2010), the Dept. of Informatics and Telecommunications, University of Athens, Greece (2010-2012), and the Center of Research and Technology Hellas (CERTH), Thessaloniki, Greece (2013-2015). He is recipient of an Intra-European Marie Curie Fellowship (2010-2012) and a Research Fellowship (2018-2021) from the Hellenic Foundation for Research and Innovation. His research interests lie in the broader area of wireless networking and performance analysis.

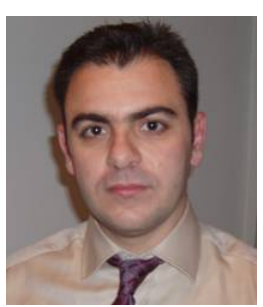

Iordanis Koutsopoulos is an Associate Professor at the Department of Informatics of Athens University of Economics and Business (AUEB) in Athens, Greece since 2016. He received the Diploma degree in Electrical and Computer Engineering from the National Technical University of Athens (NTUA), Greece, in 1997 and the M.Sc. and Ph.D. degrees in Electrical and Computer Engineering from the University of Maryland, College Park (UMCP), MD, USA, in 1999 and 2002, respectively. He has served as Assistant Professor (2013-2016) with AUEB, and Assistant Professor (2010-2013) and Lecturer (2005-2010) with the Department of Electrical and Computer Engineering, University of Thessaly. $\mathrm{He}$ received the single-investigator European Research Council (ERC) competition runner-up award for the project "RECITAL: Resource Management for Self-coordinated Autonomic Wireless Networks" (2012-2015). He is a senior member of IEEE. His research interests are in the general area of network control and optimization, with applications in mobile crowdsensing, wireless networks, social networks, online platforms, smart energy grid and cloud computing systems.

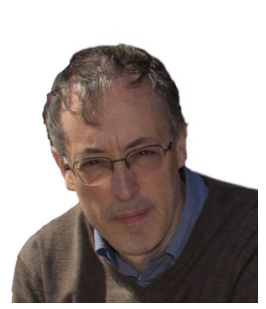

Leandro Navarro is associate Professor at the Computer Architecture Department of UPC. He received his Ph.D. from UPC in 1992. Research interests include the design of scalable and cooperative Internet services and applications. He coordinates the CNDS (Computer Networks and Distributed Systems) research group at UPC and participated in several EU research projects such as FET Catnets, SORMA, Grid4All. He coordinates the Erasmus Mundus Joint Doctorate in Distributed Computing (EMJD-DC). He is also executive board member of the Association for Progressive Communications (www.apc.org). 


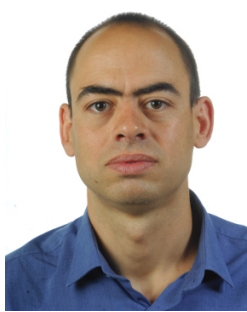

Roger Baig Vias received his degree in Industrial Engineering (2002) at the Universitat Politcnica de Catalunya (UPC) and currently is doing a $\mathrm{PhD}$ at the same University. In 2011, he joined the Foundation for the Neutral, Free and Open Network guifi.net as a researcher. He has been volunteering in the guifi.net community network since 2006 . There, he has actively contributed in many aspects such as organizing community events, promoting projects, giving talks, etc. and has gained a broad knowledge about community networks. His current research interests are focused on community networks, including dynamic routing protocols, socio-economics and management of community networks.

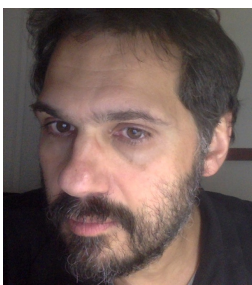

Dimitris Boucas is a postdoctoral research fellow at the Faculty of Media, Arts and Design, University of Westminster in the UK. He is currently working on the EU-funded project netCommons, which examines community networks as complementary or alternative to the standard Internet. Dimitris has a background in both computing and social sciences, with a degree in sociology from the Open University, $\mathrm{UK}$, a MSc in science and technology policy from the University of Sussex, and a PhD in information society from the LSE. He has published on information society theory and policy and media policy and has extensive teaching experience in information society, media and communication theory and policy, social media innovation management and qualitative research methods. He has taught at various Universities, including the LSE, the University of Westminster, City University of London, the University of Paris (Dauphine) and the University of Piraeus.

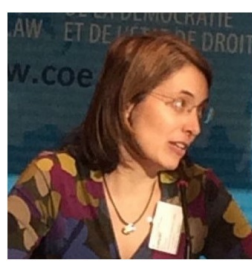

Maria Michalis received the Ph.D. degree in Communication Policy from City University, London, in 1997. She is an expert on European Union media policy and is currently Associate Professor in Communication Policy at the University of Westminster, London. She is author of Governing European Communications (Lexington, 2007) and numerous book chapters and academic articles in journals such as Media, Culture and Society; European Journal of Communication; Review of International Political Economy; International Journal of Digital Television and Telecommunications Policy. At present she is researching the interplay between the technological convergence of television and the Internet, policy and business models, with a focus on public service media. She is a VLV (Voice of the Listener and Viewer UK) Trustee and is involved in the EU Horizon 2020 research project on Internet community networks (http://netcommons.eu/). She was Secretary General of the International Association for Media and Communication Research (IAMCR, 2012-2016) and is now vice chair of the Media Industries \& Cultural Production Section of the European Communication Research and Education Association (ECREA).

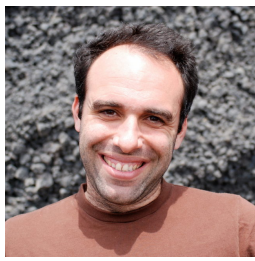

Panayotis Antoniadis is the co-founder of the nonprofit organization NetHood. He has an interdisciplinary profile with background on the design and implementation of distributed systems (Computer Science Department, University of Crete), Ph.D. on the economics of peer-to-peer networks (Athens University of Economics and Business), post-doc on policies for the federation of shared virtualized infrastructures (Pierre and Marie Curie University, UPMC, Paris), and interdisciplinary research on the role of ICTs for bridging the virtual with the physical space in cities (ETH Zurich). NetHood is an interdisciplinary organization that aims to design and develop tools for self-organization and conviviality, bringing together different forms of commoning in the city: community networks, complementary currencies, cooperative housing, social infrastructures, and community supported agriculture. It also aims to bridge the digital with the physical space and academic research with civic action, through its participation in three EU Horizon2020 projects: http://mazizone.eu, http://netcommons.eu, and http://heteropolitics.net 